\title{
Aggregation in environmental systems - Part 2: Catchment mean transit times and young water fractions under hydrologic nonstationarity
}

\author{
J. W. Kirchner ${ }^{1,2}$ \\ ${ }^{1}$ ETH Zürich, Zurich, Switzerland \\ ${ }^{2}$ Swiss Federal Research Institute WSL, Birmensdorf, Switzerland
}

Correspondence to: J. W. Kirchner (kirchner@ethz.ch)

Received: 20 February 2015 - Published in Hydrol. Earth Syst. Sci. Discuss.: 18 March 2015

Revised: 26 October 2015 - Accepted: 4 December 2015 - Published: 19 January 2016

\begin{abstract}
Methods for estimating mean transit times from chemical or isotopic tracers (such as $\mathrm{Cl}^{-}, \delta^{18} \mathrm{O}$, or $\delta^{2} \mathrm{H}$ ) commonly assume that catchments are stationary (i.e., timeinvariant) and homogeneous. Real catchments are neither. In a companion paper, I showed that catchment mean transit times estimated from seasonal tracer cycles are highly vulnerable to aggregation error, exhibiting strong bias and large scatter in spatially heterogeneous catchments. I proposed the young water fraction, which is virtually immune to aggregation error under spatial heterogeneity, as a better measure of transit times. Here I extend this analysis by exploring how nonstationarity affects mean transit times and young water fractions estimated from seasonal tracer cycles, using benchmark tests based on a simple two-box model. The model exhibits complex nonstationary behavior, with striking volatility in tracer concentrations, young water fractions, and mean transit times, driven by rapid shifts in the mixing ratios of fluxes from the upper and lower boxes. The transit-time distribution in streamflow becomes increasingly skewed at higher discharges, with marked increases in the young water fraction and decreases in the mean water age, reflecting the increased dominance of the upper box at higher flows. This simple two-box model exhibits strong equifinality, which can be partly resolved by simple parameter transformations. However, transit times are primarily determined by residual storage, which cannot be constrained through hydrograph calibration and must instead be estimated by tracer behavior.
\end{abstract}

Seasonal tracer cycles in the two-box model are very poor predictors of mean transit times, with typical errors of sev- eral hundred percent. However, the same tracer cycles predict time-averaged young water fractions $\left(F_{\mathrm{yw}}\right)$ within a few percent, even in model catchments that are both nonstationary and spatially heterogeneous (although they may be biased by roughly $0.1-0.2$ at sites where strong precipitation seasonality is correlated with precipitation tracer concentrations). Flow-weighted fits to the seasonal tracer cycles accurately predict the flow-weighted average $F_{\mathrm{yw}}$ in streamflow, while unweighted fits to the seasonal tracer cycles accurately predict the unweighted average $F_{\mathrm{yw}}$. Young water fractions can also be estimated separately for individual flow regimes, again with a precision of a few percent, allowing direct determination of how shifts in a catchment's hydraulic regime alter the fraction of water reaching the stream by fast flowpaths. One can also estimate the chemical composition of idealized "young water" and "old water" end-members, using relationships between young water fractions and solute concentrations across different flow regimes. These results demonstrate that mean transit times cannot be estimated reliably from seasonal tracer cycles and that, by contrast, the young water fraction is a robust and useful metric of transit times, even in catchments that exhibit strong nonstationarity and heterogeneity.

\section{Introduction}

In a companion paper (Kirchner, 2016, hereafter referred to as Paper 1), I pointed out that although catchments are pervasively heterogeneous, we often model them, and inter- 
pret measurements from them, as if they were homogeneous. This makes our measurements and models vulnerable to socalled "aggregation error", meaning that they yield inconsistent results at different levels of aggregation. I illustrated this general problem with the specific example of mean transit times (MTTs) estimated from seasonal tracer cycles in precipitation and discharge. Using simple numerical experiments with synthetic data, I showed that these MTT estimates will typically exhibit strong bias and large scatter when they are derived from spatially heterogeneous catchments. Given that spatial heterogeneity is ubiquitous in real-world catchments, these findings pose a fundamental challenge to the use of MTTs to characterize catchment behavior.

In Paper 1 I also showed that seasonal tracer cycles in precipitation and streamflow can be used to estimate the young water fraction $F_{\mathrm{yw}}$, defined as the fraction of discharge that is younger than a threshold age of approximately $2-3$ months. I further showed that $F_{\mathrm{yw}}$ estimates, unlike MTT estimates, are robust against extreme spatial heterogeneity. Thus, Paper 1 demonstrates the feasibility of determining the proportions of "young" and "old" water ( $F_{\mathrm{yw}}$ and $1-F_{\mathrm{yw}}$, respectively) in spatially heterogeneous catchments.

But real-world catchments are not only heterogeneous. They are also nonstationary: their travel-time distributions shift with changes in their flow regimes, due to shifts in the relative water fluxes and flow speeds of different flowpaths (e.g., Kirchner et al., 2001; Tetzlaff et al., 2007; Hrachowitz et al., 2010; Botter et al., 2010; Van der Velde et al., 2010; Birkel et al., 2012; Heidbüchel et al., 2012; Peters et al., 2014). This nonstationarity is more than simply a time-domain analogue to the heterogeneity problem explored in Paper 1, because variations in flow regime may alter both the transit-time distributions of individual flowpaths and the mixing ratios between them. Intuition suggests that catchment nonstationarity could play havoc with estimates of MTTs, and perhaps also with estimates of the young water fraction.

This paper explores three central questions. First, does nonstationarity lead to aggregation errors in MTT and thus to bias or scatter in MTT estimates derived from seasonal tracer cycles? Second, is the young water fraction $F_{\mathrm{yw}}$ also vulnerable to aggregation errors under nonstationarity or is it relatively immune, like it is to aggregation errors arising from spatial heterogeneity? Third, can either MTT or $F_{\mathrm{yw}}$ be estimated reliably from seasonal tracer cycles, in catchments that are both nonstationary and heterogeneous, as real catchments are?

In keeping with the spirit of the approach developed in $\mathrm{Pa}$ per 1, here I explore the consequences of catchment nonstationarity through simple thought experiments. These thought experiments are based on a simple two-compartment conceptual model (Fig. 1). This model greatly simplifies the complexities of real-world catchments, but it is sufficient to illustrate the key issues at hand. It is not intended to simulate the behavior of a specific real-world catchment, and thus its

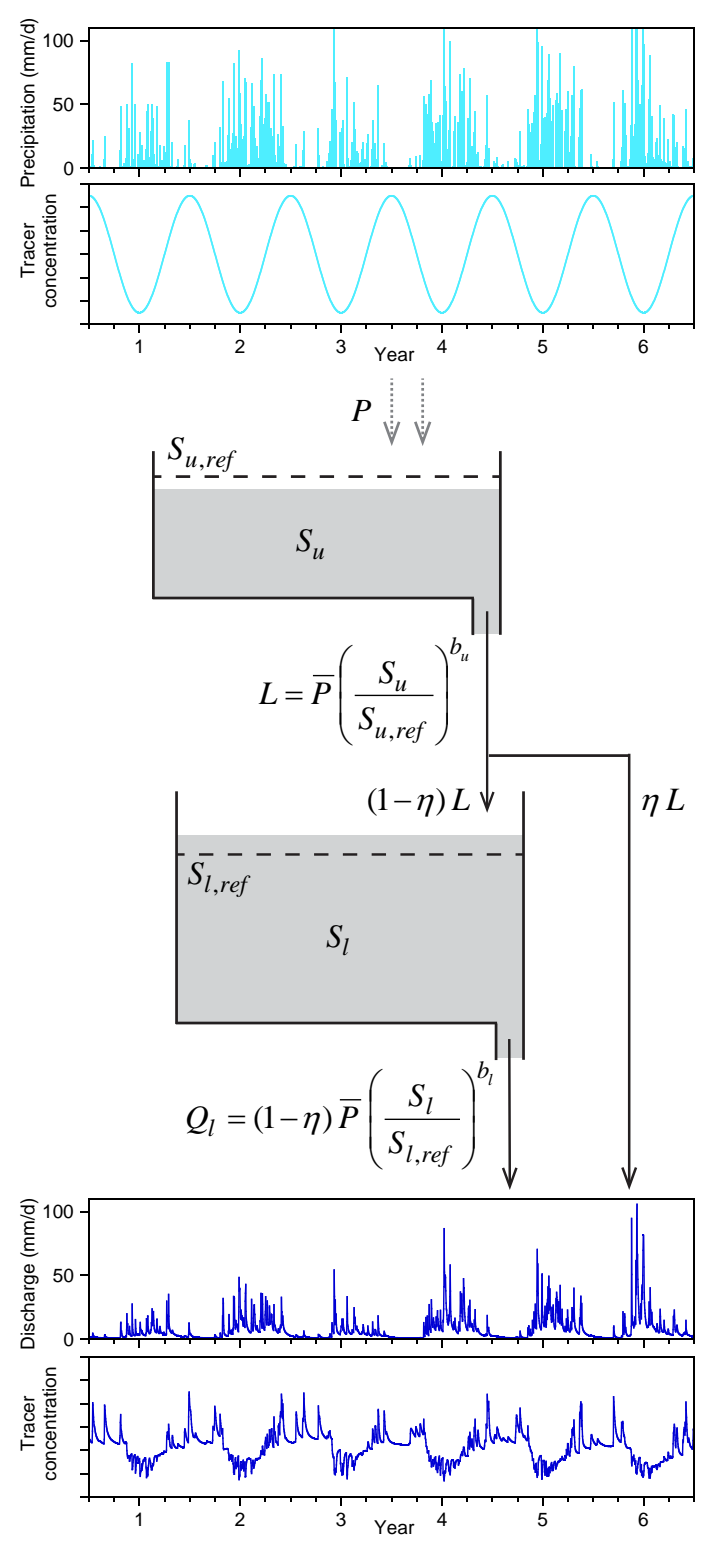

Figure 1. Schematic diagram of conceptual model. Drainage from the upper and lower boxes is determined by power functions of the storage volumes $S_{\mathrm{u}}$ and $S_{1}$ (depicted by gray, shaded regions) as ratios of the reference storage levels $S_{\mathrm{u} \text {,ref }}$ and $S_{1, \text { ref }}$ (depicted by dashed lines). The partition coefficient splits the upper box drainage $L$ into direct discharge and infiltration to the lower box.

"goodness of fit" to any particular catchment time series is unimportant. Instead, its purpose is to simulate how nonstationary dynamics may influence tracer concentrations across wide ranges of catchment behavior and thus to serve as a numerical "test bed" for exploring how catchment nonstationarity affects our ability to infer catchment transit times from tracer concentrations. One can of course construct more complicated and (perhaps) realistic models, but that is not the point here. The point here is to explore the consequences 
of catchment nonstationarity, in the context of one of the simplest possible models which nonetheless exhibits a wide range of nonstationary behaviors.

\section{A simple conceptual model for exploring nonstationarity}

\subsection{Structure and basic equations}

The model catchment consists of two compartments, an upper box and a lower box (Fig. 1). In typical conceptual models the upper box might represent soil water storage and the lower box might represent groundwater, but for the present purposes it is unnecessary to assign the two boxes to specific domains in the catchment. The upper box storage $S_{\mathrm{u}}$ is filled by precipitation $P$, and drains at a leakage rate $L$ that is a power function of storage; for simplicity, evapotranspiration is ignored. Thus, storage in the upper box evolves according to

$\frac{\mathrm{d} S_{\mathrm{u}}}{\mathrm{d} t}=P-L=P-k_{\mathrm{u}} S_{\mathrm{u}}^{b_{\mathrm{u}}}$,

where the coefficient $k_{\mathrm{u}}$ and the exponent $b_{\mathrm{u}}$ are parameters. A third parameter $0<\eta<1$ partitions the leakage $L$ from the upper box into an amount $\eta L$ that flows directly to discharge and an amount $(1-\eta) L$ that recharges the lower box. The lower box storage $S_{1}$ is recharged by leakage from the upper box and drains to streamflow at a discharge rate $Q_{1}$ that is another power function of storage:

$\frac{\mathrm{d} S_{1}}{\mathrm{~d} t}=(1-\eta) L-Q_{1}=(1-\eta) L-k_{1} S_{1}^{b_{1}}$,

where the coefficient $k_{1}$ and the exponent $b_{1}$ are the final two parameters. The stream discharge is the sum of the contributions from the upper and lower boxes, or

$Q_{\mathrm{S}}=\eta L+Q_{1}$.

All storages are in millimeters of water equivalent depth, and all fluxes are in millimeters per day. The age distribution in each box is explicitly tracked at daily resolution for the youngest 90 days and by accounting for the aggregate "age mass" (Bethke and Johnson, 2008) of each box's water that is older than 90 days. The young water fraction $F_{\mathrm{yw}}$ is calculated as the fraction of water in each box that is up to (and including) 69 days old; this threshold age equals 0.189 years, which was shown in Paper 1 to be the theoretical youngwater threshold age for seasonal cycles in systems with exponential transit-time distributions.

Discharge from both boxes is assumed to be non-ageselective, meaning that discharge is taken proportionally from each part of the age distribution; thus, the flow from each box will have the same tracer concentration, the same young water fraction $F_{\mathrm{yw}}$, and the same mean age as the averages of those quantities in that box (at that moment in time).
Tracer concentrations and mean ages are tracked under the assumption that both boxes are each well-mixed but also separate from one another, so their tracer concentrations and water ages will differ. The tracer concentrations, young water fractions, and mean water ages in streamflow are the fluxweighted averages of the contributions from the two boxes.

The model is solved on a daily time step, using a weighted combination of the partly implicit trapezoidal method (for greater accuracy) and the fully implicit backward Euler method (for guaranteed stability). Details of the solution scheme are outlined in Appendix A.

\subsection{Parameters and initialization}

The drainage coefficients $k_{\mathrm{u}}$ and $k_{1}$ are problematic as model parameters, because their values and dimensions are strongly dependent on the exponents $b_{\mathrm{u}}$ and $b_{1}$. Therefore, I instead parameterize the model drainage functions by the (dimensionless) exponents $b_{\mathrm{u}}$ and $b_{\mathrm{l}}$ and by the (dimensional) "reference" storage values $S_{\mathrm{u}, \text { ref }}$ and $S_{\mathrm{l}, \text { ref. }}$. These reference values represent the storage levels at which the drainage rates of each box will equal their long-term average input rates. That is, $S_{\mathrm{u}, \text { ref }}$ is the level of upper-box storage at which the leakage rate $L$ equals the long-term average input rate $\bar{P}$. Likewise, $S_{1, \text { ref }}$ is the level of lower-box storage at which the discharge rate $Q_{1}$ equals the average rate of recharge $(1-\eta) \bar{L}$ (which, due to conservation of mass in the upper box, also equals $(1-\eta) \bar{P})$. The drainage function coefficients are calculated from the reference storage values as follows:

$$
\begin{array}{ll}
k_{\mathrm{u}} S_{\mathrm{u}}^{b_{\mathrm{u}}}=\bar{P}, & k_{\mathrm{u}}=\bar{P} S_{\mathrm{u}, \mathrm{ref}}^{-b_{\mathrm{u}}}, \\
k_{1} S_{1, \text { ref }}^{b_{1}}=(1-\eta) \bar{P}, & k_{1}=(1-\eta) \bar{P} S_{1, \text { ref }}^{-b_{1}} .
\end{array}
$$

Expressing $k_{\mathrm{u}}$ and $k_{1}$ in this way is equivalent to writing the drainage equations for the two boxes in dimensionless form, with the drainage rate expressed with reference to the longterm input rate as follows:

$$
\begin{aligned}
& \frac{L}{\bar{P}}=\left(\frac{S_{\mathrm{u}}}{S_{\mathrm{u}, \mathrm{ref}}}\right)^{b_{\mathrm{u}}}, \\
& \frac{Q_{1}}{(1-\eta) \bar{P}}=\left(\frac{S_{1}}{S_{1, \text { ref }}}\right)^{b_{1}} .
\end{aligned}
$$

One advantage of this approach is that, whereas the drainage coefficients $k_{\mathrm{u}}$ and $k_{1}$ have no clear meaning and their numerical values and dimensions can vary wildly, the reference storage values are measured in millimeters of water equivalent depth, and their interpretation is straightforward. A further advantage of this approach is that it provides for varying degrees of residual storage without requiring any additional parameters to do so. Because $S_{\mathrm{u}, \text { ref }}$ and $S_{\mathrm{l}, \text { ref }}$ are the storage levels at which long-term mass balance is achieved, they represent the equilibria around which $S_{\mathrm{u}}$ and $S_{1}$ will tend to fluctuate, with the range of those fluctuations largely determined by the variability in precipitation rates and by the stiffness of 

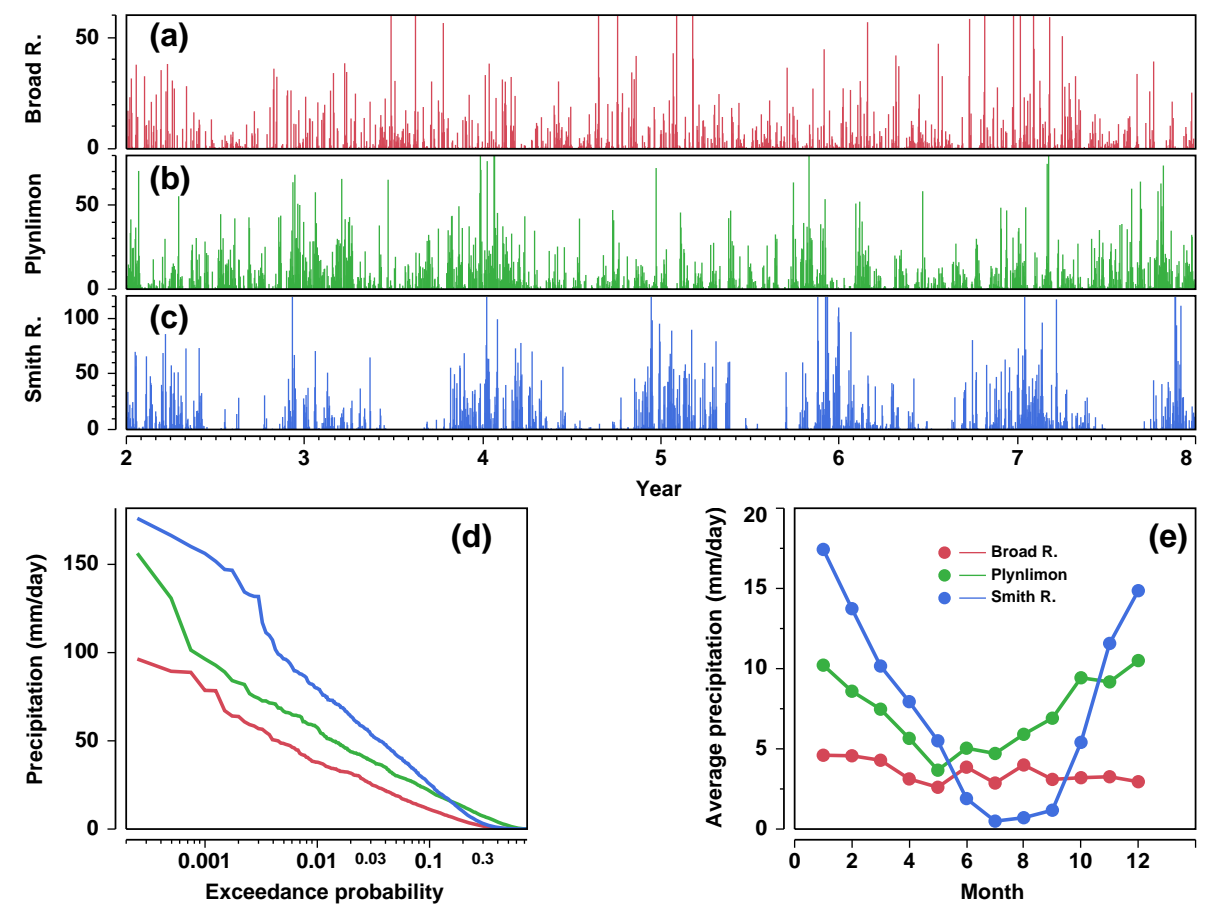

Figure 2. Excerpts of daily precipitation records used to drive the model: (a) Broad River, Georgia, USA (humid temperate climate; Köppen climate zone Cfa) in red, (b) Plynlimon, Wales (humid maritime climate; Köppen climate zone Cfb) in green, and (c) Smith River, California, USA (Mediterranean climate; Köppen climate zone Csb) in blue. Axes are expanded to make typical storms visible; thus, the largest storms, some of which extend to roughly twice the axis limits, are cut off. Exceedance probability (d) shows a steeper magnitude-frequency relationship for Smith River than for the other two records. Monthly precipitation averages (e) show clear differences in seasonality among the three sites.

the drainage functions, as specified by the exponents $b_{\mathrm{u}}$ and $b_{1}$ (see Sect. 3.2).

The storages are initialized at the reference values $S_{\mathrm{u}, \mathrm{ref}}$ and $S_{1, \text { ref. }}$. The tracer concentrations are initialized at equilibrium (that is, at the volume-weighted mean of the precipitation tracer concentration). Likewise, the mean ages in each box are initialized at their steady-state equilibrium values: $S_{\mathrm{u}, \text { ref }} / \bar{P}$ in the upper box and $S_{\mathrm{u}, \text { ref }} / \bar{P}+S_{\mathrm{l}, \mathrm{ref}} /[\bar{P}(1-\eta)]$ in the lower box. After a 1-year spin-up period, I run the model for 10 more years; the results for those 10 years are reported here.

\subsection{Parameter ranges and precipitation drivers}

Here I drive the model with three different real-world rainfall time series, representing a range of climatic regimes: a humid maritime climate with frequent rainfall and moderate seasonality (Plynlimon, Wales; Köppen climate zone $\mathrm{Cfb}$ ), a Mediterranean climate marked by wet winters and very dry summers (Smith River, California, USA; Köppen climate zone $\mathrm{Csb}$ ), and a humid temperate climate with very little seasonal variation in average rainfall (Broad River, Georgia, USA; Köppen climate zone Cfa). Figure 2 shows the contrasting frequency distributions and seasonalities of the three rainfall records. The Plynlimon rain gauge data were provided by the Centre for Ecology and Hydrology (UK), and the Smith River and Broad River precipitation data are reanalysis products from the MOPEX (Model Parameter Estimation Experiment) project (Duan et al., 2006; ftp://hydrology.nws.noaa.gov/pub/gcip/mopex/ US_Data/). The use of these real-world precipitation time series obviates the need to generate statistically realistic synthetic precipitation to drive the model.

The model used here shares a similar overall structure with many other conceptual models (e.g., Benettin et al., 2013), with several simplifications. However, although the model used here is typical in many respects, I will use it in an unusual way. Typically, one calibrates a model to reproduce the behavior of a real-world catchment and then draws inferences about that catchment from the parameters and behavior of the calibrated model. Here, however, the model is not intended to represent any particular real-world system. Instead, the model itself is the system under study, across wide ranges of parameter values, because the goal is to gain insight into how nonstationarity affects general patterns of tracer behavior. Thus, the fidelity of the model in representing any particular catchment is not a central issue.

For the simulations shown here, the drainage exponents $b_{\mathrm{u}}$ and $b_{1}$ are randomly chosen from uniform distributions spanning the ranges of $1-20$ and $1-50$, respectively, the parti- 
tioning coefficient $\eta$ is randomly chosen from a uniform distribution ranging from 0.1 to 0.9 , and the reference storage levels $S_{\mathrm{u}, \text { ref }}$ and $S_{\mathrm{l}, \text { ref }}$ are randomly chosen from a uniform distribution of logarithms spanning the ranges of 20-500 and 500-10000 mm, respectively. These parameter distributions are designed to encompass a wide range of possible behaviors, including both strong and damped response to rainfall inputs and small and large residual storage. To illustrate the behavior of the model for one concrete case, I use a "reference" parameter set with values taken from roughly the middle of each of these parameter distributions $\left(b_{\mathrm{u}}=10, b_{1}=20\right.$, $\eta=0.5, S_{\mathrm{u}, \mathrm{ref}}=100 \mathrm{~mm}$, and $S_{1, \mathrm{ref}}=2000 \mathrm{~mm}$ ). These parameter values are not "better" than any others in any particular sense; they are simply a point of reference (hence the name) for discussing the model's behavior.

\section{Results and discussion}

\subsection{Nonstationarity in the two-box model}

My main purpose is to use the simple two-box model to explore how catchment nonstationarity affects our ability to infer water ages from tracer time series. I will take up that issue beginning in Sect. 3.3. As background for that analysis, however, it is helpful to first characterize the nonstationary behavior of the simple model system.

Figure 3 shows excerpts from the time series generated by the model with the Smith River (Mediterranean climate) precipitation time series and the reference parameter set. One can immediately see that the upper and lower boxes have markedly different mean ages (Fig. 3e), young water fractions (Fig. 3d), and tracer concentrations (Fig. 3c), which also vary differently through time. Tracer concentrations in the upper box (the orange line in Fig. 3c) show a blocky, irregular pattern, remaining almost constant during periods of little rainfall, and then changing rapidly when the box is episodically flushed by large precipitation events. The lower box's tracer concentrations (the red line in Fig. 3c) are much more stable than the upper box's, because its mean residence time is roughly 40 times longer ( $S_{1, \text { ref }}$ is 20 times $S_{\mathrm{u}, \mathrm{ref}}$, and with $\eta=0.5$ the flux through the lower box is only half of the flux through the upper box). Because much more rain falls during the winters than the summers, the mean tracer concentration in the lower box is closer to the winter concentrations than the summer concentrations. During the wet winter season, rapid flushing keeps the young water fraction near $100 \%$ in the upper box (the orange line in Fig. 3d) and can raise the young water fraction to $30-40 \%$ in the lower box (the red line in Fig. 3d). Conversely, during the late summer the young water fraction in the upper box temporarily dips to $50 \%$ or less, and the young water fraction in the lower box declines to nearly zero. The small volume in the upper box means that its water age (the orange line in Fig. 3e) is only a small fraction of a year. The mean water age in the lower box (the red line in Fig. 3e) is much older and exhibits both seasonal variation and inter-annual drift, reflecting year-to-year variations in total precipitation. Thus, the two components of this simple system have strongly contrasting characteristics and behavior. These internal states of any real-world system would not be observable, except as they are reflected in the volume and composition of streamflow.

In this regard, the most striking feature of Fig. 3 is the volatility of the tracer concentrations, young water fractions, and mean transit times in discharge (the dark blue lines in Fig. 3c-e), as the mixing ratio between the two boxes (Fig. 3b) shifts in response to precipitation events. This mixing ratio is not a simple function of discharge (Fig. 4c); instead it is both hysteretic and nonstationary, varying in response both to precipitation forcing and to the antecedent moisture status of the two boxes (and thus to the prior history of precipitation). This dependence on prior precipitation reflects the fact that the boxes typically retain their water age and tracer signatures over timescales much longer than the timescale of hydraulic response, because their residual storage is large compared to their dynamic storage (see Sect. 3.2). As a result, both the young water fraction and mean age of discharge and storage are widely scattered functions of discharge (Fig. 4a, b). Likewise, there is no simple relationship between either the young water fraction or mean age in storage and the corresponding quantities in discharge (Fig. 4d), although there is a strong overall bias toward water in discharge being much younger than the average water in storage.

Even though drainage from each box is non-age-selective (that is, the young water fraction and mean age in drainage from each box are identical to those in storage), this is emphatically not true at the level of the two-box system, because the two boxes account for different proportions of discharge than of storage. Furthermore, because the fractional contributions to streamflow from the (younger, smaller) upper box and the (older, larger) lower box are highly variable, the water age and young water fraction in discharge are not only strongly biased, but also highly scattered, indicators of the same quantities in storage (Fig. 4d).

The aggregate long-term implications of these dynamics are evident in the marginal (time-averaged) age distributions of storage and discharge (Fig. 5). From Fig. 5 it is immediately obvious that the age distributions in discharge are strongly skewed toward young ages, compared to the age distributions in storage, both for each box individually and for the catchment as a whole. This skew toward young ages arises for two main reasons. First, although drainage from each box is not age-selective, more outflow occurs during periods of stronger precipitation forcing and thus shorter residence times. Thus, the average ages of the outflow and the storage can differ greatly. Second, under high-flow conditions a larger proportion of discharge is derived from the upper box (which has a relatively short transit time), and at base flow more discharge is derived from the lower box (which 

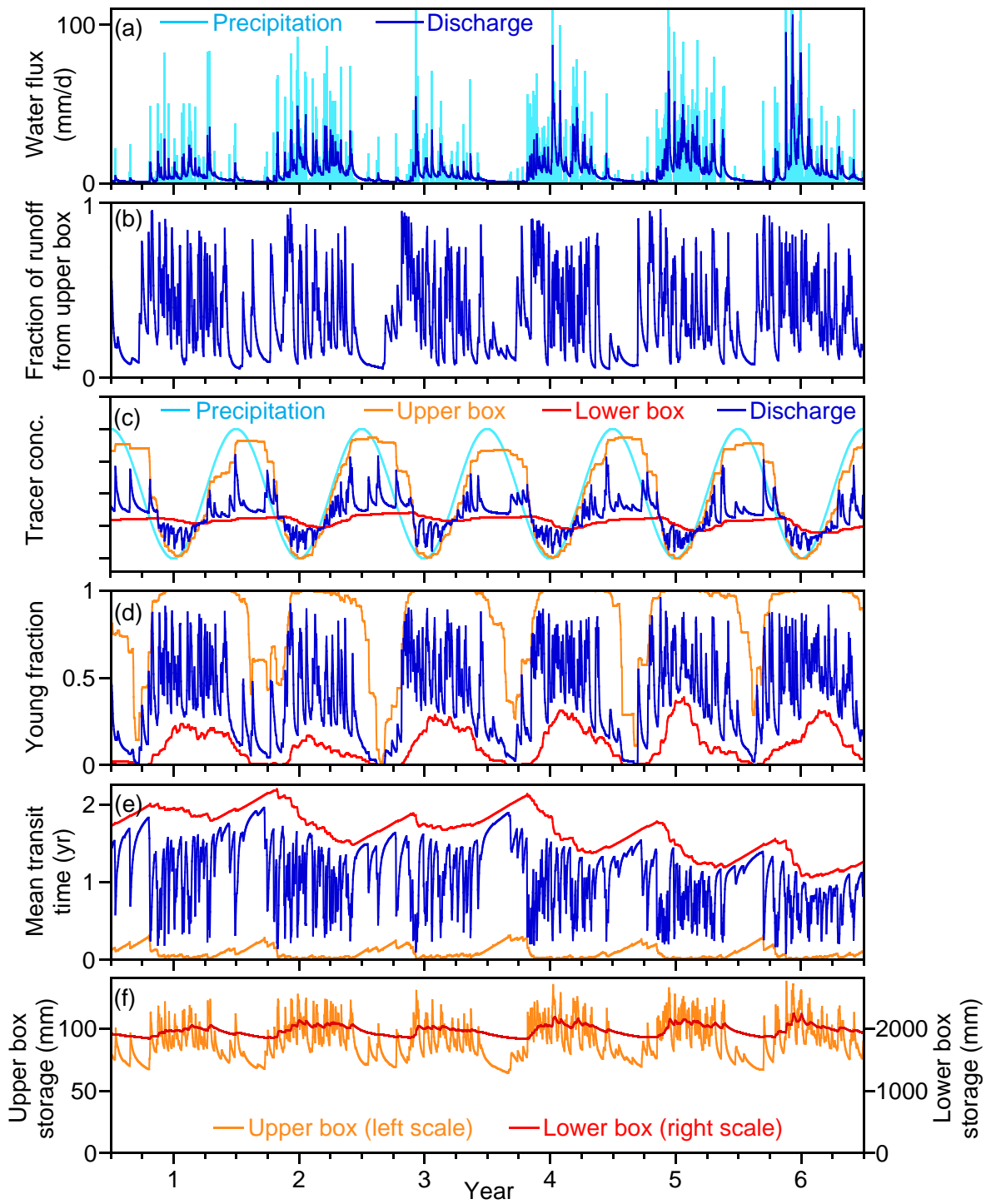

Figure 3. Illustrative time series from the two-box model, using the reference parameter set and the Smith River (Mediterranean climate) precipitation time series. Responses to precipitation events (a) entail rapid shifts in the proportions of discharge coming from the upper and lower boxes (b). The smaller, upper box, shown in orange, has a larger young water fraction (d) and a younger mean age (e) than the larger, lower box, shown in red, and thus its tracer concentration (c) is less lagged and damped relative to the hypothetical precipitation concentration, shown by the cosine wave in (c). Mean ages increase (e) and young water fractions decrease (d), in both boxes, throughout the dry summer periods. The proportions of streamflow originating from the upper and lower boxes shift dramatically in response to transient precipitation inputs; thus, the tracer concentrations, young water fractions, and mean ages in discharge (dark blue, c-e) vary widely between the time-varying end-members represented by the upper and lower boxes. Storage volumes fluctuate in a relatively narrow range (f) while discharge varies by orders of magnitude, because the drainage rates from both boxes are strongly nonlinear functions of storage. Thus, both boxes have sizeable residual storage, which is not drained even under extreme low-flow conditions.

has a larger volume and a relatively long transit time). Thus, the short-transit-time components of the system dominate the discharge, while the long-transit-time components of the system dominate the storage. As a result, the mean age in discharge will generally be much younger than the mean age in whole-catchment storage, and likewise the young water fraction in discharge will be much larger than the young water fraction in storage. Note that this is the opposite of what one would expect from conceptual models like those of Botter (2012), in which the mean water age in discharge either equals the mean age in storage (for well-mixed systems) or is older than the mean age in storage (for piston-flow systems).

More generally, and more importantly, these results imply that estimates of water age in streamflow cannot be translated straightforwardly into estimates of water age in storage. Instead, they may underestimate the age of water in 

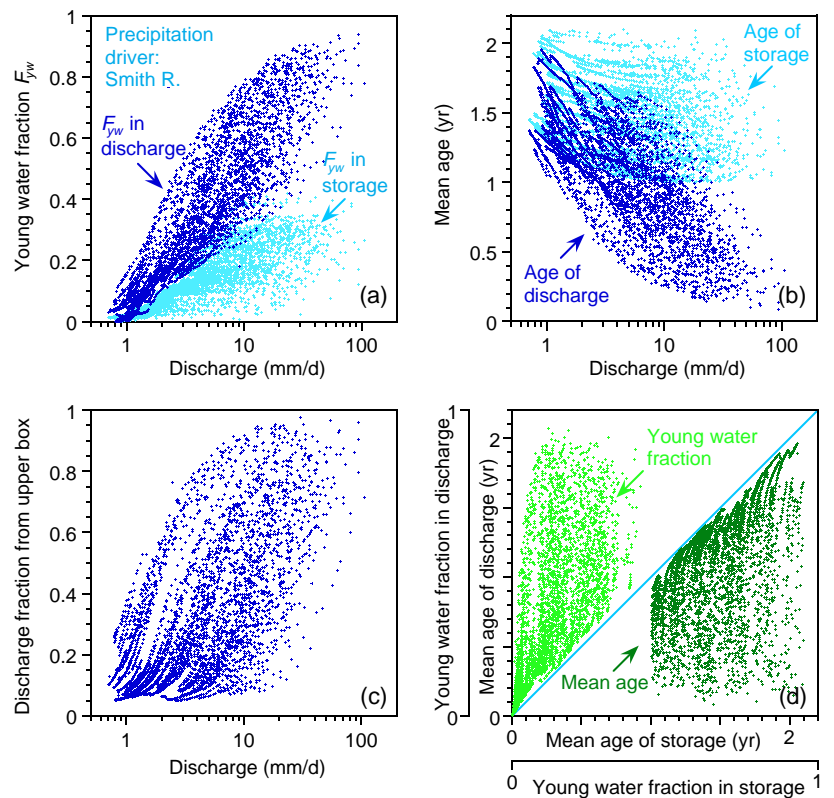

Figure 4. Daily values of young water fractions $F_{\mathrm{yw}}(\mathbf{a})$ and mean water ages (b) in storage (light blue) and discharge (dark blue) in the two-box model with reference parameter values and Smith River (Mediterranean climate) precipitation. The young water fraction and mean age are both highly scattered functions of discharge (a, b), as is the fractional contribution from the upper box to streamflow (c), reflecting the effects of variations in antecedent rainfall. The average age and $F_{\mathrm{yw}}$ of water in discharge are strongly biased, and highly scattered, measures of the same quantities in storage (d).

storage by large factors, although in the particular example shown in Fig. 5, the difference is only about a factor of 2 . Three closely related theoretical functions have recently been proposed to quantify the long-recognized (Kreft and Zuber, 1978) disconnect between the age distributions in storage and in discharge. These include the time-dependent StorAge Selection (SAS) function $\omega_{Q}$ of Botter et al. (2011), the Storage Outflow Probability (STOP) functions of Van der Velde et al. (2012), and the rank StorAge Selection (rSAS) function of Harman (2015). While these functions are all grounded in elaborate theoretical frameworks, it remains to be seen whether they can be reliably estimated in practice using realworld data.

A further implication of the analysis above is that the marginal age distributions are not exponential, even for individual boxes, and even though drainage from each box is not age-selective. In steady state, non-age-selective drainage (i.e., the well-mixed assumption) would yield an exponential distribution of ages in the upper box and in the short-time age distribution in streamflow. However, when the system is not in steady state and we aggregate its behavior over time, we are combining different age distributions from different moments in time with different precipitation forcing. This creates an aggregation error in the time domain, in the sense that the steady-state approximation will be a misleading guide to the non-steady-state behavior of the system, even on average. That is, even over timescales where inputs equal outputs and the long-term average fluxes are essentially constant and thus the steady-state approximation, on average, holds the average behavior of the non-steady-state system can differ significantly from the average behavior of an equivalent steady-state system.

One can further explore these issues by examining the marginal (time-averaged) age distributions for separate ranges of discharge (Fig. 6). Figure 6 shows that at higher discharges, age distributions in streamflow are much more strongly skewed toward younger ages, reflecting the increased dominance of the upper box at higher flows. For the upper half of all discharges, the age distributions are more skewed than exponential; that is, they plot as upwardcurving lines in Fig. 6b. For the top $25 \%$ of discharges, water ages follow approximate power-law distributions, plotting as nearly straight lines in Fig. 6c. The slopes of these lines are steeper than 1, however, implying that the distributions must deviate from this trend at very short ages; otherwise their integrals (i.e., their cumulative distributions) would become infinite. It is important to note the mean ages quoted in Fig. 6a imply that the tails of the distributions all extend far beyond the plot axes, which are truncated at 90 days. Note also that the distributions shown in Fig. 6 have different shapes in different flow regimes, suggesting that the model's high-flow behavior is not simply a re-scaled transform of its low-flow behavior.

\subsection{Residual storage and the disconnect between transit time and hydraulic response timescales}

The model's complex, nonstationary water age and tracer dynamics arise from the disconnect between the timescales of hydraulic response and catchment storage in each box, and from the divergence in both these timescales between the two boxes. These contrasting timescales can be estimated through simple scaling and perturbation analyses, as outlined in this section.

Total catchment storage consists of two components: the dynamic storage that is linked to discharge fluctuations through storage-discharge relationships like Eqs. (6)-(7), plus the residual or "passive" storage that remains when discharge has declined to very slow rates. The range of dynamic storage exerts an important control on timescales of catchment hydrologic response, while the much larger residual (or "passive") storage has little effect on water fluxes but is an essential control on residence times (Kirchner, 2009; Birkel et al., 2011).

In real-world catchments, sharply nonlinear storagedischarge relationships (Kirchner, 2009) guarantee that dynamic storage will be small compared to residual storage. This behavior is mirrored in the model, where if Eqs. (6) and (7) are strongly nonlinear (i.e., if the drainage exponents $b_{\mathrm{u}}$ 

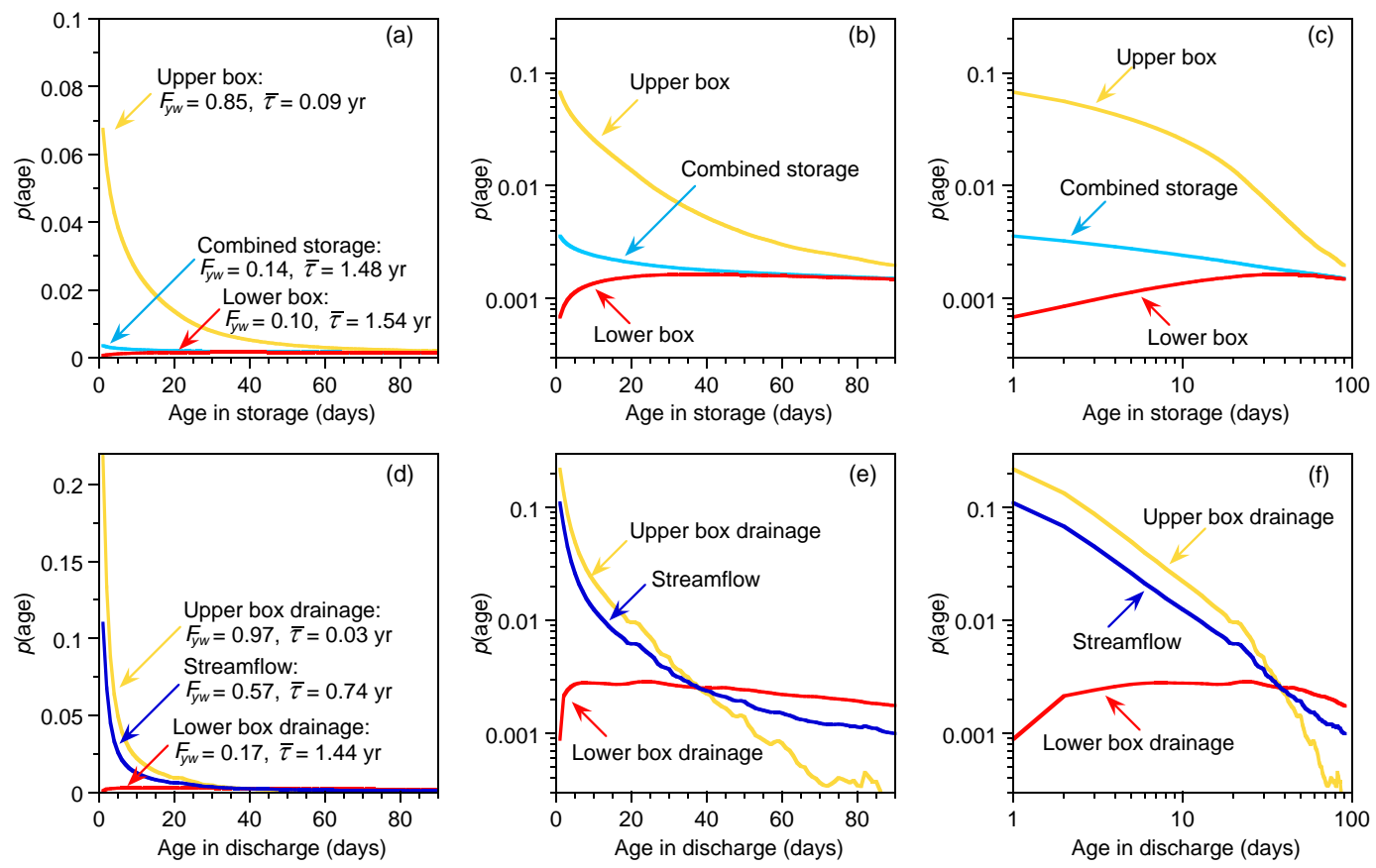

Figure 5. Marginal (time-averaged) age distributions in storage (a-c) and drainage (d-f) in the reference case simulation (Fig. 3), shown on linear (a, d), log-linear (b, e), and double-log $(\mathbf{c}, \mathbf{f})$ axes. Distributions in drainage (lower panels) are skewed toward younger ages than the storage distributions that they come from (upper panels). This arises, even though drainage is not age-selective, because storage is flushed more quickly (and thus is younger) during periods of higher discharge. Age distributions in the upper box, combined storage, and streamflow are more skewed than exponentials (i.e., they are upward-curving in the middle panels). The age distributions in the combined storage and streamflow (blue lines) are approximate power laws; i.e., they are nearly straight in the right-hand panels, with markedly different power-law slopes. The light blue line in the upper panels shows the age distribution of the combined upper and lower boxes, which resembles the age distribution of the lower box because the reference parameter values imply that the lower box comprises about $95 \%$ of total storage. However, direct drainage from the upper box comprises $50 \%$ of streamflow; thus, the streamflow age distribution (shown by the dark blue line in lower panels) reflects the strong skew of the upper box age distribution. Although both boxes are well mixed and have nearly constant volumes, the age distribution of discharge clearly differs from the distribution that would be expected in steady state, which would be exponential in the short-time limit.

and $b_{1}$ are much greater than 1), the volumes in the upper and lower boxes will vary by only a small fraction of their reference storage values $S_{\mathrm{u}, \text { ref }}$ and $S_{\mathrm{l} \text {,ref }}$ (e.g., Fig. 3f). They will remain relatively constant because, when the drainage exponents $b_{\mathrm{u}}$ and $b_{1}$ are large, the storage volumes cannot become much smaller than $S_{\mathrm{u}, \text { ref }}$ and $S_{1, \text { ref }}$ without drainage rates falling to near zero (thus stopping further decreases in storage) and, conversely, the storage volumes also cannot become much larger than $S_{\mathrm{u}, \text { ref }}$ and $S_{1, \text { ref }}$ without drainage rates becoming very high (thus stopping further increases in storage). Thus, $S_{\mathrm{u}, \text { ref }}$ and $S_{1, \text { ref }}$ will be good approximations to the residual storage volume, whenever the drainage exponents are much greater than 1 .

One can express this concept more quantitatively (though only approximately) using a simple perturbation analysis. A first-order Taylor expansion of Eqs. (6) and (7) shows directly that the fractional variability in drainage rates and storage are related by the drainage exponents in the two boxes:

$$
\begin{aligned}
& \frac{\Delta L}{\bar{P}} \approx b_{\mathrm{u}} \frac{\Delta S_{\mathrm{u}}}{S_{\mathrm{u}, \mathrm{ref}}}, \\
& \frac{\Delta Q_{1}}{(1-\eta) \bar{P}} \approx b_{1} \frac{\Delta S_{1}}{S_{\mathrm{l}, \mathrm{ref}}} .
\end{aligned}
$$

The variability in drainage rates from the upper and lower boxes, denoted as $\Delta L$ and $\Delta Q_{1}$, will be controlled by the temporal variability in precipitation; thus, for a given precipitation climatology, the dynamic variability in storage (denoted as $\Delta S_{\mathrm{u}}$ and $\Delta S_{1}$ ) will scale according to the ratios $S_{\mathrm{u}, \text { ref }} / b_{\mathrm{u}}$ and $S_{\mathrm{l}, \mathrm{ref}} / b_{1}$. For example, when the model is driven by Smith River precipitation and uses the reference parameters (Fig. 3), the variability in discharge from the lower box, as measured by its standard deviation, is $3.7 \mathrm{~mm}$ day $^{-1}$, nearly equal to the average lower box discharge of $3.8 \mathrm{~mm} \mathrm{day}^{-1}$. Because the reference value of $b_{1}$ is 20, Eq. (9) implies that the standard deviation of lower box storage should be approximately $1 / 20$ th of the reference storage $S_{1, \text { ref }}$, or roughly $100 \mathrm{~mm}$. Consistent with this estimate, the actual standard deviation of $S_{1}$ is $84 \mathrm{~mm}$ or about 

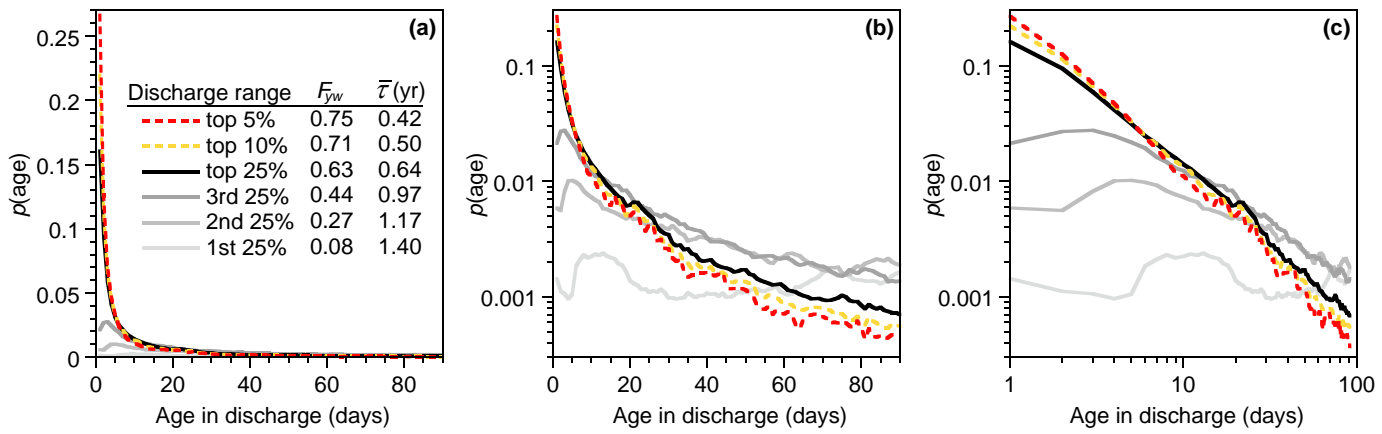

Figure 6. Marginal (time-averaged) transit-time distributions (TTDs) for selected ranges of daily discharges in the two-box model, with the reference parameter set and Smith River (Mediterranean climate) precipitation forcing, on linear (a), log-linear (b), and double-log (c) axes. The TTD becomes increasingly skewed at higher discharges (a), with a marked increase in the young water fraction $F_{\text {yw }}$ and decrease in the mean water age $\bar{\tau}$. For the upper half of all discharges, the age distribution is upward-curving on log-linear axes (b), implying that it is more skewed than exponential. Discharges in the top $25 \%$ and above have approximately power-law age distributions, plotting as nearly straight lines on double-log axes (c).

$4 \%$ of the total. Figure $3 \mathrm{f}$ shows that at least $90 \%$ of $S_{1 \text {,ref }}$ is residual storage that never drains during the 10-year simulation, roughly consistent with the perturbation analysis.

The perturbation analysis also yields estimates for the timescale of hydraulic response (which controls how "flashy" the discharge will be), through a rearrangement of Eqs. (8) and (9) as follows:

$\frac{\Delta S_{\mathrm{u}}}{\Delta L} \approx \frac{S_{\mathrm{u}, \mathrm{ref}}}{b_{\mathrm{u}} \bar{P}}$ (hydraulic response timescale, upper box),

$\frac{\Delta S_{1}}{\Delta Q_{1}} \approx \frac{S_{1, \text { ref }}}{b_{1}(1-\eta) \bar{P}}$ (hydraulic response timescale, lower box).

Again, using the reference parameter values and Smith River precipitation (for which $\bar{P}$ is roughly $7.6 \mathrm{~mm} \mathrm{day}^{-1}$ ), Eqs. (10) and (11) imply a hydraulic response time of roughly 1.3 days (for $b_{\mathrm{u}}=10$ ) in the upper box and of roughly 26 days (for $b_{1}=20$ ) in the lower box. These timescales are factors $b_{\mathrm{u}}$ and $b_{1}$ smaller than the steady-state mean transit times, which are determined by the ratios between the volumes and water fluxes,

$\frac{S_{\mathrm{u}, \mathrm{ref}}}{\bar{P}}$ (steady-state mean transit time, upper box),

$\frac{S_{1, \text { ref }}}{(1-\eta) \bar{P}}$ (steady-state mean transit time, lower box).

From Eqs. (12) and (13) one can also directly estimate the steady-state mean travel time in the combined discharge, as the weighted average of streamflow derived directly from the upper box, and water that flows through the upper and lower boxes in series,

$\eta \frac{S_{\mathrm{u}, \text { ref }}}{\bar{P}}+(1-\eta)\left(\frac{S_{\mathrm{u}, \text { ref }}}{\bar{P}}+\frac{S_{\mathrm{l}, \mathrm{ref}}}{(1-\eta) \bar{P}}\right)=\frac{S_{\mathrm{u}, \mathrm{ref}}+S_{\mathrm{l}, \mathrm{ref}}}{\bar{P}}$,

which is the expected result for any system at steady state: regardless of its internal configuration, the mean transit time in any steady-state system will equal the ratio between its storage volume and its throughput rate. For the reference parameter set and Smith River precipitation, Eq. (14) becomes $(100 \mathrm{~mm}+2000 \mathrm{~mm}) / 7.6 \mathrm{~mm} \mathrm{day}^{-1}$, or roughly 0.76 years, in good agreement with the whole-catchment mean transit time of 0.74 years determined from age tracking (see Fig. 5d). Note, however, that the distribution of these transit times will be markedly different from the exponential distribution that would be expected in steady state. This makes estimating mean transit times from tracer fluctuations difficult, as shown in Sect. 3.3.

Equations (12) and (13) imply that the mean transit times in the upper and lower boxes should be roughly 13 days (or 0.036 years) and 529 days (or 1.45 years), respectively, in good agreement with the mean transit times of 0.03 and 1.44 years determined from age tracking (Fig. 5d). However, Eqs. (10) and (11) imply that these transit times will differ by factors of 10 and 20 (the values of $b_{\mathrm{u}}$ and $b_{1}$, respectively) from the hydraulic response timescales that regulate catchment runoff response. The disconnect between hydraulic response times and mean transit times is the counterpart, in lumped conceptual models, to the disconnect between the velocity of water transport and the celerity of hydraulic head propagation in more realistic, physically extended systems (Beven, 1982; Kirchner et al., 2000; McDonnell and Beven, 2014). This contrast between hydraulic response times and mean transit times (or dynamic and total storage, or celerity and velocity) is a simple explanation for the apparent paradox of prompt discharge of old water during storm events (Kirchner, 2003).

\subsection{Inferring MTT and $F_{\mathrm{yw}}$ from seasonal tracer cycles in nonstationary catchments}

The analysis above shows that the simple two-box model gives hydrograph and tracer behavior that is complex and 
nonstationary (Figs. 3-6). Furthermore, even this simple fiveparameter model exhibits strong equifinality (Appendix B). Much of this equifinality can be alleviated (compare Figs. B1 and B2) through parameter transformations based on the perturbation analysis outlined above. However, because the timescales of catchment storage and hydraulic response are controlled by different combinations of parameters, parameter calibration to the hydrograph cannot constrain the storage volumes or streamwater age (Figs. B2, B3). These model results demonstrate general principles that have been recognized for years: (a) the hydrograph responds to and, thus, can help to constrain dynamic storage but not passive storage; and (b) because passive storage is often large, timescales of hydrologic response and catchment water storage are decoupled from one another, such that water ages cannot be inferred from hydrograph dynamics. Thus, for understanding how catchments store and mix water, tracer data are essential.

But how should these tracer data be used? One approach is to explicitly include tracers in a catchment model and calibrate that model against both the hydrograph and the tracer chemograph (e.g., Birkel et al., 2011; Benettin et al., 2013; Hrachowitz et al., 2013). The usefulness of that approach depends on whether the model parameters can be constrained and, more importantly, whether the model structure adequately characterizes the system under study (which is usually unknown, and possibly unknowable). Except in multi-model studies, it will be unclear how much the conclusions depend on the particular model that was used and on the particular way that it was fitted to the data. Furthermore, adequate tracer data for calibrating such models are rare, particularly because dynamic models require input data with no gaps. The mismatch between model complexity and data availability means that, in some cases, all the data are used for calibration and validation must be skipped, leaving the reproducibility of the model results unclear (e.g., Benettin et al., 2015).

For all of these reasons, there will be an ongoing need for methods of inferring water ages that have modest data requirements and that are not dependent on specific model structures and parameters. Sine-wave fitting of seasonal tracer cycles, for example, is not based on a particular mechanistic model but, instead, is based on a broader conceptual framework in which stream output is some convolution of previous precipitation inputs. That premise is of course open to question but, nevertheless, seasonal tracer cycles (of, e.g., ${ }^{18} \mathrm{O},{ }^{2} \mathrm{H}$, and $\mathrm{Cl}^{-}$) have been widely used to estimate mean catchment transit times (see McGuire and McDonnell (2006) and references therein), largely because this particular method has modest data requirements. In particular, it does not need unbroken records of either precipitation inputs or streamflow outputs.

As detailed more fully in Paper 1, the seasonal tracer cycle method is based on the principle that when one convolves a sinusoidal tracer input with a TTD, one obtains a sinusoidal output that is damped and phase-lagged by an amount that depends on the shape of the TTD and also on its scale, as expressed, for example, by its MTT. Conventionally one assumes an exponential TTD, which is the steady-state solution for a well-mixed reservoir. More generally, one might assume that transit times are gamma-distributed, recognizing that the exponential distribution is a special case of the gamma distribution (with the shape factor $\alpha$ equal to 1). A sinusoidal tracer cycle that has been convolved with a gamma TTD will be damped and phase-lagged as described in Eqs. (8) and (9) of Paper 1. These equations can then be inverted to infer the shape and scale of the TTD from the seasonal tracer cycles in precipitation and streamflow.

The procedure is as follows. One first measures the amplitudes and phases of the seasonal tracer cycles in precipitation and streamflow using Eqs. (4)-(6) of Paper 1. If one assumes an exponential TTD, one can estimate the MTT directly from the amplitude ratio $A_{\mathrm{S}} / A_{\mathrm{P}}$ in streamflow and precipitation using Eq. (10) of Paper 1 with $\alpha=1$. Where I plot results from this procedure (i.e., Fig. 7) the corresponding axis will say "MTT inferred from $A_{\mathrm{S}} / A_{\mathrm{P}}$ ". This is the approach that is conventionally used in the literature. Alternatively, as I showed in Sect. 4.4 of Paper 1, one can use the tracer cycle amplitude ratio $A_{\mathrm{S}} / A_{\mathrm{P}}$ and phase shift $\varphi_{\mathrm{S}}-\varphi_{\mathrm{P}}$ to jointly estimate the shape factor $\alpha$ and the MTT (assuming the TTD is gamma-distributed, which is less restrictive than assuming that it is exponential). To do this one estimates the shape factor $\alpha$ from $A_{\mathrm{S}} / A_{\mathrm{P}}$ and $\varphi_{\mathrm{S}}-\varphi_{\mathrm{P}}$, using Eq. (11) from Paper 1, and then estimates the scale factor $\beta$ using Eq. (10) from Paper 1; the MTT is $\alpha$ times $\beta$. MTTs estimated by this procedure are shown in Figs. 10-12 as "MTT inferred from $A_{\mathrm{S}} / A_{\mathrm{P}}$ and $\varphi_{\mathrm{S}}-\varphi_{\mathrm{P}} "$.

Paper 1 shows that both of these MTT measures are extremely vulnerable to aggregation bias in spatially heterogeneous catchments. Therefore, Paper 1 proposes an alternative measure of travel times: the young water fraction $F_{\mathrm{yw}}$, which is designed to be much less sensitive than MTT to aggregation artifacts. $F_{\mathrm{yw}}$ is the fraction of streamflow that is younger than a specified threshold age. For a seasonal cycle (i.e., with a period of 1 year) and reasonable range of TTD shapes, the threshold age varies between about 0.15 and 0.25 years or, equivalently, $\sim 2-3$ months (see Eq. 14 and Fig. 10 in Paper 1). As described in Sect. 2, in the model simulations the "true" $F_{\mathrm{yw}}$ is defined by a threshold age of 0.189 years (69 days), which equals the threshold age for seasonal cycles convolved with an exponential TTD.

One can use seasonal tracer cycles to infer the young water fraction following either of two strategies. As shown in Sect. 4.1 of Paper 1, in many situations $F_{\mathrm{yw}}$ is approximately equal to the amplitude ratio $A_{\mathrm{S}} / A_{\mathrm{P}}$ itself (indeed, it was designed to have this property). In figures where the amplitude ratio $A_{\mathrm{S}} / A_{\mathrm{P}}$ is used as an estimate of $F_{\mathrm{yw}}$ (e.g., Fig. 7), the axis says simply " $F_{\mathrm{yw}}$ inferred from $A_{\mathrm{S}} / A_{\mathrm{P}}$ ". Alternatively, one can use both the amplitude ratio $A_{\mathrm{S}} / A_{\mathrm{P}}$ and phase shift $\varphi_{\mathrm{S}}-\varphi_{\mathrm{P}}$ to estimate $F_{\mathrm{yw}}$, as explained in Sect. 4.4 of Pa- 

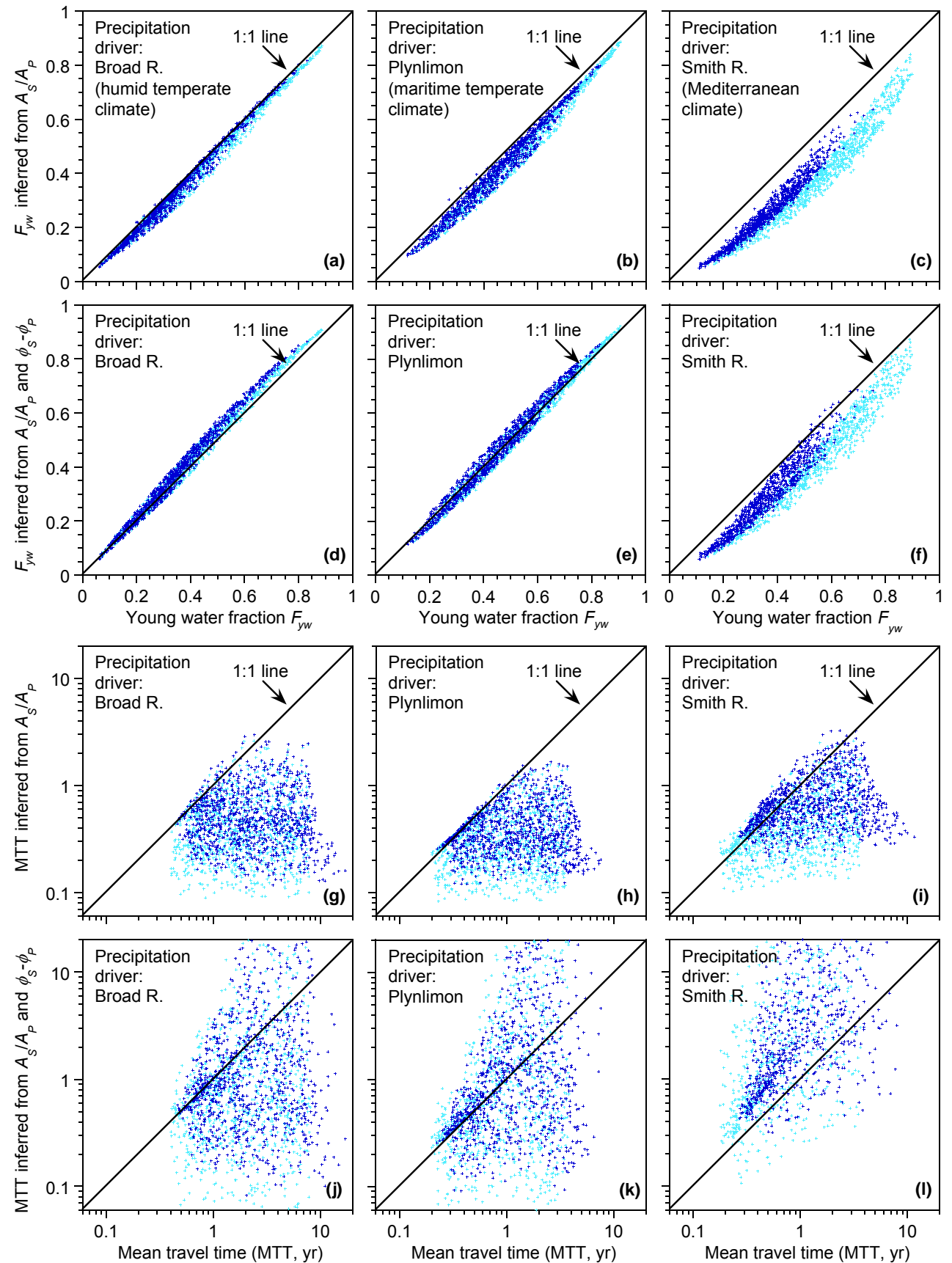

Figure 7. Young water fractions $\left(F_{\mathrm{yw}}\right.$, top panels) and mean transit times (MTT, bottom panels - note log scale) in streamflow from the two-box model. Upper panels compare the average $F_{\mathrm{yw}}$ in discharge, determined by age tracking within the model (on the horizontal axes) with the seasonal tracer cycle amplitude ratio $A_{\mathrm{S}} / A_{\mathrm{P}}(\mathbf{a}-\mathbf{c})$, and with $F_{\mathrm{yw}}$ inferred from the tracer cycle amplitude ratio $A_{\mathrm{S}} / A_{\mathrm{P}}$ and phase shift $\varphi_{\mathrm{S}}-\varphi_{\mathrm{P}}(\mathbf{d}-\mathbf{f})$. Lower panels compare the average MTT in discharge (again from age tracking) with MTT inferred from the tracer amplitude ratio $(\mathbf{g}-\mathbf{i})$ and from amplitude ratio and phase shift $(\mathbf{j}-\mathbf{l})$. Light blue points show flow-weighted average $F_{\mathrm{yw}}$ values and MTTs for each simulation, compared to estimates from flow-weighted fits to seasonal tracer cycles. Dark blue points show unweighted average $F_{\mathrm{yw}}$ values and MTTs, compared to estimates from unweighted fits to seasonal tracer cycles. Panels show results from 1000 random parameter sets and three contrasting precipitation drivers: Broad River (humid, temperate, with very little seasonality), Plynlimon (wet maritime climate with slight seasonality), and Smith River (Mediterranean climate with pronounced winter-wet, summer-dry seasonality). Seasonal tracer cycle amplitudes generally predict the average young water fraction, although they exhibit some systematic bias under strongly seasonal precipitation regimes like Smith River, where seasonal cycles in precipitation volume are correlated with seasonal cycles in tracer concentration. By contrast, mean transit-time estimates from seasonal tracer cycles are highly unreliable in all precipitation regimes. 
per 1. First, one estimates the shape factor $\alpha$ from $A_{\mathrm{S}} / A_{\mathrm{P}}$ and $\varphi_{\mathrm{S}}-\varphi_{\mathrm{P}}$ using Paper 1's Eq. (11). One then determines the threshold age $\tau_{\mathrm{yw}}$ from $\alpha$ using Paper 1's Eq. (14), and the scale factor $\beta$ from $\alpha$ and $A_{\mathrm{S}} / A_{\mathrm{P}}$ using Paper 1's Eq. (10). Lastly, one estimates $F_{\mathrm{yw}}$ as lower incomplete gamma function $\Gamma\left(\tau_{\mathrm{yw}}, \alpha, \beta\right)$ (Eq. 13 in Paper 1). Where I have followed this more complex procedure (e.g., Figs. 9-12), the figure axes say " $F_{\mathrm{yw}}$ inferred from $A_{\mathrm{S}} / A_{\mathrm{P}}$ and $\varphi_{\mathrm{S}}-\varphi_{\mathrm{P}}$ ". All of these $F_{\mathrm{yw}}$ and MTTs are intended as temporal averages, reflecting whatever conditions (e.g., precipitation climatologies or flow regimes) have shaped the seasonal cycles that are used to estimate them.

These methods for inferring the young water fraction $F_{\mathrm{yw}}$ are derived from the properties of gamma TTDs. However, as I showed in Sects. 4.2-4.3 of Paper 1, these methods reliably estimate $F_{\mathrm{yw}}$ for very wide ranges of catchment TTDs (beyond the already broad family of gamma distributions), at least in catchments that are spatially heterogeneous but time-invariant. Here I explore whether these methods are also reliable in nonstationary catchments (and, in Sect. 3.5, in catchments that are both nonstationary and spatially heterogeneous).

Figure 7 shows the true young water fractions $F_{\mathrm{yw}}$ and MTTs in discharge from the two-box model, compared to estimates of $F_{\mathrm{yw}}$ and MTT inferred from the model's seasonal tracer cycles. As Fig. $7 \mathrm{a}-\mathrm{c}$ show, the amplitude ratios $A_{\mathrm{S}} / A_{\mathrm{P}}$ of seasonal tracer cycles reliably estimate the true young water fractions in the model streamflow, across 1000 random parameter sets encompassing a very wide range of nonstationary catchment behavior. The slight underestimation bias in Fig. $7 \mathrm{a}-\mathrm{c}$ is reduced when both amplitude and phase information are used to estimate $F_{\mathrm{yw}}$ (Fig. 7d-f). Under strongly seasonal precipitation forcing (Smith River; right panels in Fig. 7), the seasonal tracer cycles underestimate $F_{\mathrm{yw}}$ by roughly $0.1-0.2$, although the predicted and observed values of $F_{\mathrm{yw}}$ remain strongly correlated. For the other two precipitation drivers (Broad River and Plynlimon), the predicted and observed values of $F_{\mathrm{yw}}$ correspond almost exactly. Thus, Fig. 7 shows that the young water fraction is relatively insensitive to aggregation error under nonstationarity, mirroring its robustness against spatial heterogeneity (as shown in Paper 1). By contrast, estimates of MTT are strongly biased and widely scattered, even on logarithmic axes (lower panels, Fig. 7).

One additional complication in nonstationary situations, compared to the time-invariant examples explored in Paper 1, is that the young water fraction $F_{\mathrm{yw}}$ and MTT can be expressed either as simple averages over time (representing the $F_{\mathrm{yw}}$ or MTT of an average day of streamflow) or as flowweighted averages (representing the $F_{\mathrm{yw}}$ or MTT of an average liter of streamflow). These quantities will not be equivalent, since higher flows will typically have higher $F_{\mathrm{yw}}$ and shorter MTTs (Figs. 3, 4). Likewise one can expect that amplitudes of flow-weighted and unweighted fits to the seasonal tracer cycles will be different. As the light blue points in
Fig. 7 show, amplitude ratios of flow-weighted fits to the seasonal tracer cycles accurately predict the flow-weighted $F_{\mathrm{yw}}$ in streamflow; likewise, as the dark blue points show, the amplitude ratios of unweighted fits accurately predict the unweighted $F_{\mathrm{yw}}$ in streamflow. The flow-weighted fits to the seasonal tracer cycles were calculated by weighted least squares, with weights proportional to streamflow or precipitation volume. (In real-world applications, a robust fitting technique like iteratively reweighted least squares (IRLS) can be used to limit the influence of outliers. An R script for performing volume-weighted IRLS is available from the author.)

The underestimation bias in $F_{\mathrm{yw}}$ observed under the Smith River precipitation forcing may arise because the assumed tracer cycle is correlated with the strong seasonality in precipitation, such that tracer concentrations peak during the summer, when almost no rain falls. Thus, the effective variability of tracer inputs to the catchment is less than one would infer from a sinusoidal fit to the precipitation tracer concentrations (and volume-weighting the fit does not help because in these synthetic precipitation data the fit is exact, so there are no residuals on which the weighting can have any effect). Because the tracer concentration amplitude overestimates the effective variability in tracer concentrations reaching the catchment, the tracer damping in the catchment is overestimated and thus the $F_{\mathrm{yw}}$ is underestimated. This underestimation bias disappears if one shifts the phase of the assumed precipitation tracer concentrations so that they peak in the spring or fall, and thus are uncorrelated with the seasonality in precipitation volumes. I have not done so here, however, because stable isotope ratios in precipitation typically peak in mid-summer at latitudes poleward of $\sim 35^{\circ}$ (Feng et al., 2009), where most catchment studies have been conducted. Thus, Fig. 7 suggests the potential for bias in $F_{\mathrm{yw}}$ estimates at sites where isotope cycles are correlated with very strong precipitation seasonality. However, even under the strongly seasonal Smith River precipitation forcing, the bias in inferred $F_{\mathrm{yw}}$ values is small compared to the a priori uncertainty in $F_{\mathrm{yw}}$ (which is on the order of 1), and small compared to the bias in inferred MTTs (which is large even on logarithmic axes).

Panels g-i of Fig. 7 compare the MTT in streamflow with estimates of MTT as they are conventionally calculated, that is, from the seasonal tracer cycle amplitude assuming an exponential TTD. These plots show that these conventional estimates are subject to a strong underestimation bias, which can exceed an order of magnitude. Some of the MTT estimates do fall close to the $1: 1$ line, but these are mostly cases in which the partition coefficient $\eta$ is very small, such that nearly all drainage from the upper box is routed through the lower box, thus transforming the two-box, nonstationary model into a nearly one-box, nearly stationary model. The strong aggregation bias in MTT under catchment nonstationarity shown in Fig. 7g-i mirrors the similarly strong bias under spatial heterogeneity that was demonstrated in Paper 1. 
The implication of Fig. 7g-i (and of Paper 1) is that many of the MTT values in the literature are likely to be underestimated by large factors and, thus, that real-world catchment MTTs are likely to be much longer than we thought. This observation raises the question: where is all that water being stored? In steady state, the storage volume must equal the discharge multiplied by the MTT (see Sect. 3.2). Thus, if we have been underestimating MTTs by large factors, then we have also been underestimating catchment storage volumes by similar multiples. Where is the storage volume that can accommodate all this water?

One possible answer is that in a non-steady-state system, the MTT decreases with increasing discharge (e.g., Fig. 4b), and the storage volume equals the discharge multiplied by the volume-weighted MTT rather than the time-averaged MTT. Because the volume-weighted MTT is less (potentially much less) than the time-averaged MTT (see also Peters et al., 2014), the implied storage volume is correspondingly smaller. Furthermore, many MTT studies in the literature have been based on tracer sampling that excludes high flows, such that they infer the mean age of baseflow rather than of the average discharge (McGuire and McDonnell, 2006). To the extent that mean baseflow discharges are lower than mean total discharges, the stored volume of baseflow water will be less than what one might overestimate by multiplying the mean total discharge by the mean baseflow age. Beyond these general considerations, however, it makes little sense to draw precise inferences based on MTT estimates that are likely to be strongly biased and widely scattered (as shown here and also in Paper 1).

It is important to recognize that the predicted $F_{\mathrm{yw}}$ values are really predictions, unlike many "predictions" from calibrated models. The horizontal axes in Fig. 7 are calculated solely from the age-tracking within the model, with no information about the tracer concentrations. Likewise, the vertical axes in Fig. 7 are calculated from the modeled tracer cycles alone, without any information about the model that generated them and in particular without any information about the modeled age of streamflow. Thus, Fig. 7 gives some basis for confidence that estimates of $F_{\mathrm{yw}}$ will also be reliable in real-world catchments, where the true "model" can never be known.

\subsection{Young water fractions in discrete flow regimes}

Figures 3 and 4 show that high-flow periods are characterized by shorter mean transit times and higher young water fractions, reflecting the increased dominance of drainage from the upper box with its younger water ages. Although instantaneous transit-time distributions (TTDs) can be highly variable and, thus, instantaneous mean transit times and young water fractions can exhibit scattered relationships with discharge (Fig. 4), the marginal (time-averaged) TTDs in Fig. 6 clearly show a systematically stronger skew toward younger water ages in higher ranges of streamflow. Thus, as Fig. 6 shows, the TTD varies in shape, not just in scale, between different flow regimes.

This observation leads naturally to the question of whether these variations in TTDs are also reflected in streamflow tracer concentrations and whether those tracer signatures can be used to draw inferences about the TTDs that characterize individual flow regimes. Figure 3 shows that high-flow periods typically exhibit wider variations in tracer concentrations, reflecting greater contributions from the upper box, which has shorter residence times and thus more labile tracer concentrations than the lower box does. To test how systematic these variations in concentrations are, I ran the model with the reference parameter set and Plynlimon (temperate maritime) precipitation forcing and separated the resulting time series into six discharge ranges. Figure 8 shows these six discharge ranges and the corresponding tracer concentrations in dark blue, superimposed on the entire discharge and concentration time series in light gray. As Fig. 8 shows, seasonal tracer cycles at higher flows are systematically less damped and phase-shifted (relative to the tracer cycle in precipitation, shown by the dotted gray line), implying shorter MTTs and larger young water fractions.

To test whether these changes in the seasonal tracer cycles are quantitatively consistent with the shifts in water age across the six flow regimes, I fitted sinusoids separately to the tracer concentrations in each individual discharge range (Fig. 8). I compared these with a single sinusoid fitted to the entire precipitation tracer time series (because it is not possible to assign discrete precipitation events to individual discharge ranges). From the resulting amplitude ratios and phase shifts for each discharge range, I then estimated $F_{\mathrm{yw}}$ values nd MTT using the methods outlined in Sect. 3.3. Figure 9 presents the results of this thought experiment, showing that the time-averaged (but flow-specific) young water fraction $F_{\mathrm{yw}}$ in each discharge range is accurately predicted by the damping and phase shift of the corresponding seasonal tracer cycle.

To test whether this result is general, I repeated this thought experiment for 200 random parameter sets and all three precipitation drivers. The results are shown in Fig. 10, with each discharge range plotted in a different color. The colors overlap because the discharge ranges, $F_{\mathrm{yw}}$ values, and MTTs all vary substantially from one parameter set to the next. The amplitudes and phase shifts of the seasonal tracer cycles predict the time-averaged young water fractions $F_{\mathrm{yw}}$ in each discharge range with reasonable accuracy (upper panels, Fig. 10). Somewhat surprisingly, the $F_{\mathrm{yw}}$ underestimation bias seen in Fig. 7c and f under the highly seasonal Smith River precipitation forcing does not arise in the predicted $F_{\mathrm{yw}}$ values for the separate discharge ranges (Fig. 10c). In contrast to the generally close correspondence between the predicted and observed $F_{\mathrm{yw}}$ values, predicted MTTs are very widely scattered for all discharge ranges and all precipitation forcings (lower panels, Fig. 10). 
Daily discharge $(\mathrm{mm} / \mathrm{d})$
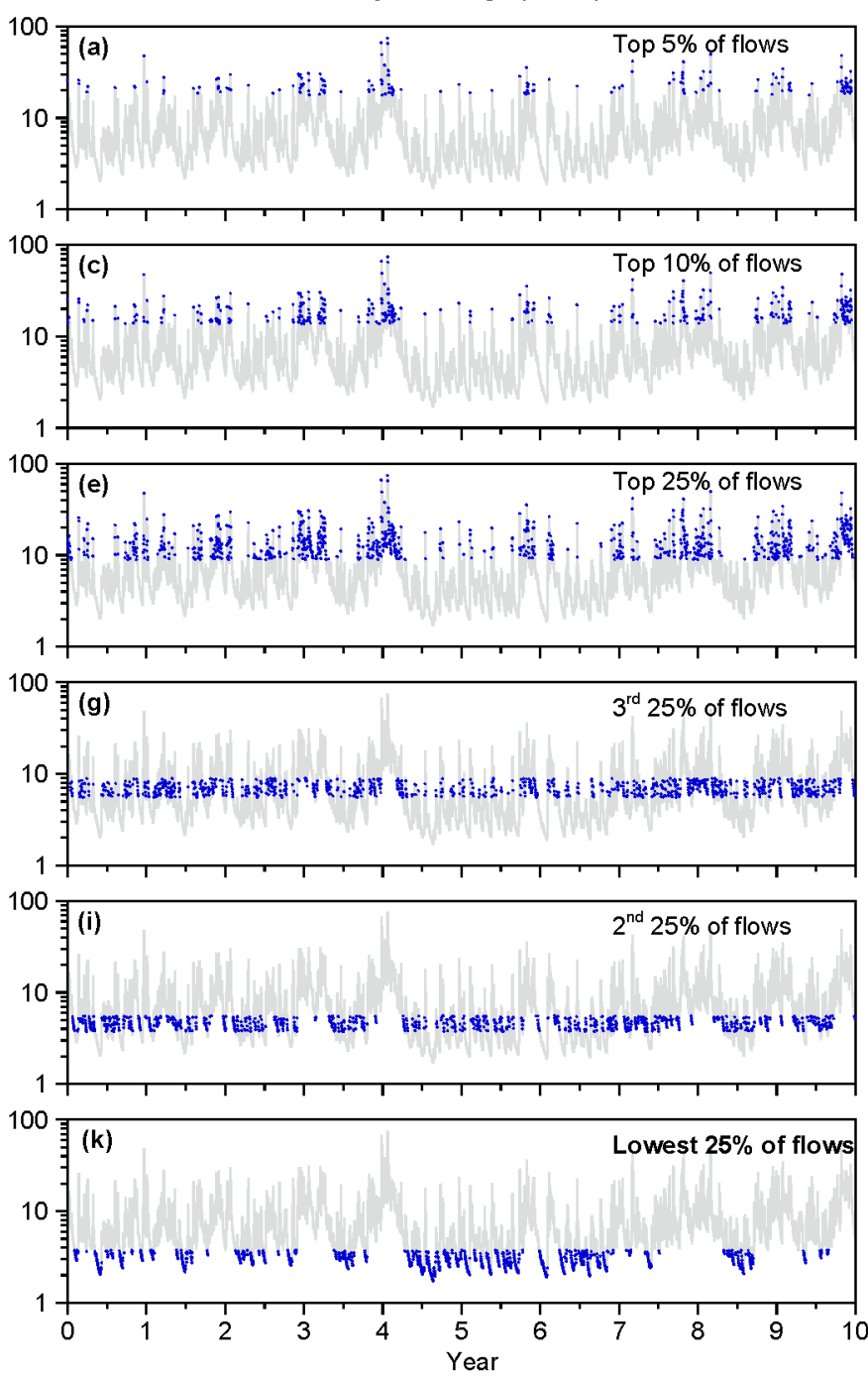

Tracer concentration in discharge (arbitrary units)
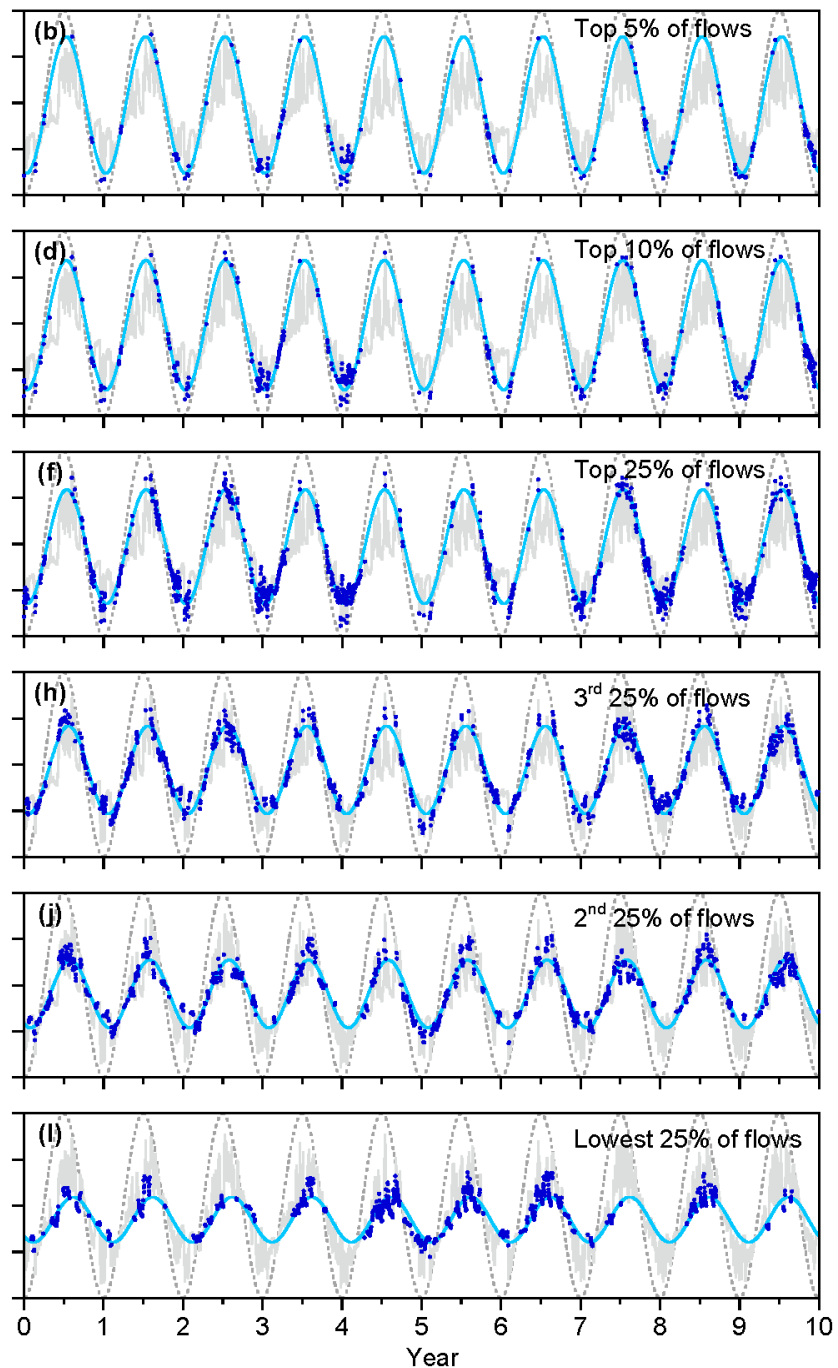

Figure 8. Daily discharges (left panels) and tracer concentrations (right panels) in streamflow from the two-box model with reference parameter values and Plynlimon precipitation forcing. Individual discharge ranges and corresponding tracer concentrations are highlighted in dark blue. In the right-hand panels, precipitation tracer concentrations are shown by dashed gray lines and sinusoidal fits to streamflow tracer concentrations are shown in light blue. At higher discharges, tracer cycles are less damped and less phase-shifted, indicating greater fractions of young water in streamflow.

\subsection{Combined effects of nonstationarity and spatial heterogeneity}

Paper 1 explored whether mean travel times and young water fractions can be reliably inferred from tracer dynamics in spatially heterogeneous (but stationary) catchments, composed of diverse subcatchments with different (but timeinvariant) TTDs. The sections above have presented a similar analysis for nonstationary (but spatially homogeneous) catchments. However, real-world catchments are not either heterogeneous or nonstationary; instead they are both heterogeneous and nonstationary. That is, their subcatchments each exhibit nonstationary dynamics that may vary greatly from one to the next. To explore the combined effects of nonstationarity and spatial heterogeneity, I merged the approach developed in Paper 1 with the model developed in Sect. 2.

As illustrated in Fig. 11, I ran eight copies of the nonstationary model developed in Sect. 2, representing eight different tributaries, each with a different, randomly chosen parameter set. I chose the number eight to provide a reasonable degree of complexity and heterogeneity while preserving a reasonable degree of computational efficiency. I supplied the same precipitation forcing (Fig. 11a) to all eight models (Fig. 11b) to simulate the behavior of the eight hypothetical tributary streams (Fig. 11c). I then simulated the merging of these streams by averaging their discharges, and 


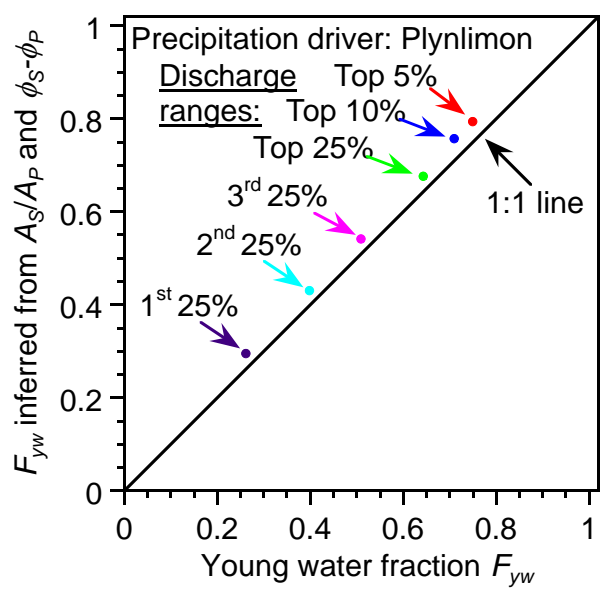

Figure 9. Time-averaged, flow-specific young water fractions $F_{\mathrm{yw}}$ for the six discharge ranges shown in Fig. 8, measured by age tracking in the model (with Plynlimon precipitation forcing and the reference parameter set), compared to $F_{\mathrm{yw}}$ values estimated from the amplitude ratios $A_{\mathrm{S}} / A_{\mathrm{P}}$ and phase shifts $\varphi_{\mathrm{S}}-\varphi_{\mathrm{P}}$ of the tracer cycles shown in Fig. 8.

taking volume-weighted averages of their tracer concentrations, young water fractions, and water ages (Fig. 11d). Because the instantaneous flows from the eight tributaries vary differently through time, their mixing ratios also fluctuate. The individual random parameter sets create a wide range of model structures at the whole-catchment level, since the eight parallel subcatchments in Fig. 11 jointly comprise a 16-box, 40-parameter model incorporating wide ranges of large and small reservoirs with varying degrees of nonlinearity.

In any spatially heterogeneous catchment (which is to say, any real-world catchment), one will typically only have observations from the merged whole-catchment streamflow (i.e., the blue time series in Fig. 11d). One will typically have no information about the behavior of the individual tributaries (i.e., the colored time series in Fig. 11c), and if one did, then those tributaries would themselves have their own spatially heterogeneous tributary streams or flowpaths, and so on. Thus, the heterogeneity of any real-world catchment will remain poorly quantified (and possibly even unrecognized), and rigorously reductionist attempts to fully characterize such complex multiscale heterogeneity would be impractical.

Thus, we face the problem: how much can we infer from the behavior of the merged whole-catchment streamflow, given that it originates from processes that are heterogeneous and nonstationary (to a degree that is unknown and unknowable)? Figure 12 explores this general question in the specific context of young water fractions and mean travel times, presenting results from 200 iterations of the heterogeneous nonstationary model shown in Fig. 11 with all three precipitation drivers. In Fig. 12 the merged streamflow is separated into discrete flow regimes, following the approach outlined in Sect. 3.4. As Fig. 12 shows, $F_{\mathrm{yw}}$ values inferred from the tracer cycles in each discharge range accurately predict the true fraction of young water in that discharge range, as determined from age tracking.

Figure 12 is analogous to Fig. 10, with the difference that Fig. 10 shows model runs for individual random parameter sets, whereas Fig. 12 shows results from eight runs merged together. Merging the model outputs will tend to average out the idiosyncrasies of the individual parameter sets, which is why the clusters of points in Fig. 12 are more compact than the corresponding point clouds in Fig. 10. As a result, the individual discharge ranges overlap less in Fig. 12 than in Fig. 10. The compact scatterplots shown in Fig. 12 show only small deviations from the $1: 1$ line for estimates of the young water fraction $F_{\mathrm{yw}}$. By contrast, estimates of mean transit times in Fig. 12 exhibit substantial bias and scatter (note the logarithmic axes in Fig. 12d-f).

\subsection{Hydrological and hydrochemical implications of young water fractions}

The results reported above, together with the results reported in Paper 1, show that unlike mean transit times, young water fractions can be estimated reliably from seasonal tracer cycles in catchments that are spatially heterogeneous, nonstationary, or both. These findings then raise the obvious question: we can measure young water fractions reliably, but what are they good for? One answer is that young water fractions can be considered as a catchment characteristic, analogous (but far from equivalent) to MTT. In theory MTT should be particularly useful as a catchment descriptor, because the MTT times the mean annual discharge yields the total catchment storage. But because estimates of MTT will often be substantially in error, estimates of catchment storage derived from MTT are likely to be equally unreliable. If the shape of the TTD were known, of course, there would be a clear functional relationship between MTT and $F_{\mathrm{yw}}$, and one could be calculated from the other. But if the shapes of the TTD were known, estimating the MTT itself would also be easy; the problem in estimating the MTT is the fact that the TTD's shape - particularly the length of its tail - is poorly constrained by tracer data. This is why $F_{\mathrm{yw}}$ can be estimated much more reliably than MTT. $F_{\mathrm{yw}}$, like the amplitude of the seasonal tracer cycle, depends on the relative proportions of younger and older water, but is insensitive to how old the "older" water is. MTT depends critically on the age of the older water, which cannot be reliably determined because it has almost no effect on the seasonal tracer cycle (or on more elaborate convolution analyses; see Seeger and Weiler, 2014).

Because the young water fraction is indifferent to the age of the older water, it cannot be used to estimate residual storage. What $F_{\mathrm{yw}}$ estimates, instead, is the fraction of water reaching the stream by relatively fast (less than $\sim 2-3$ month) flowpaths. In the context of the present model, this is re- 

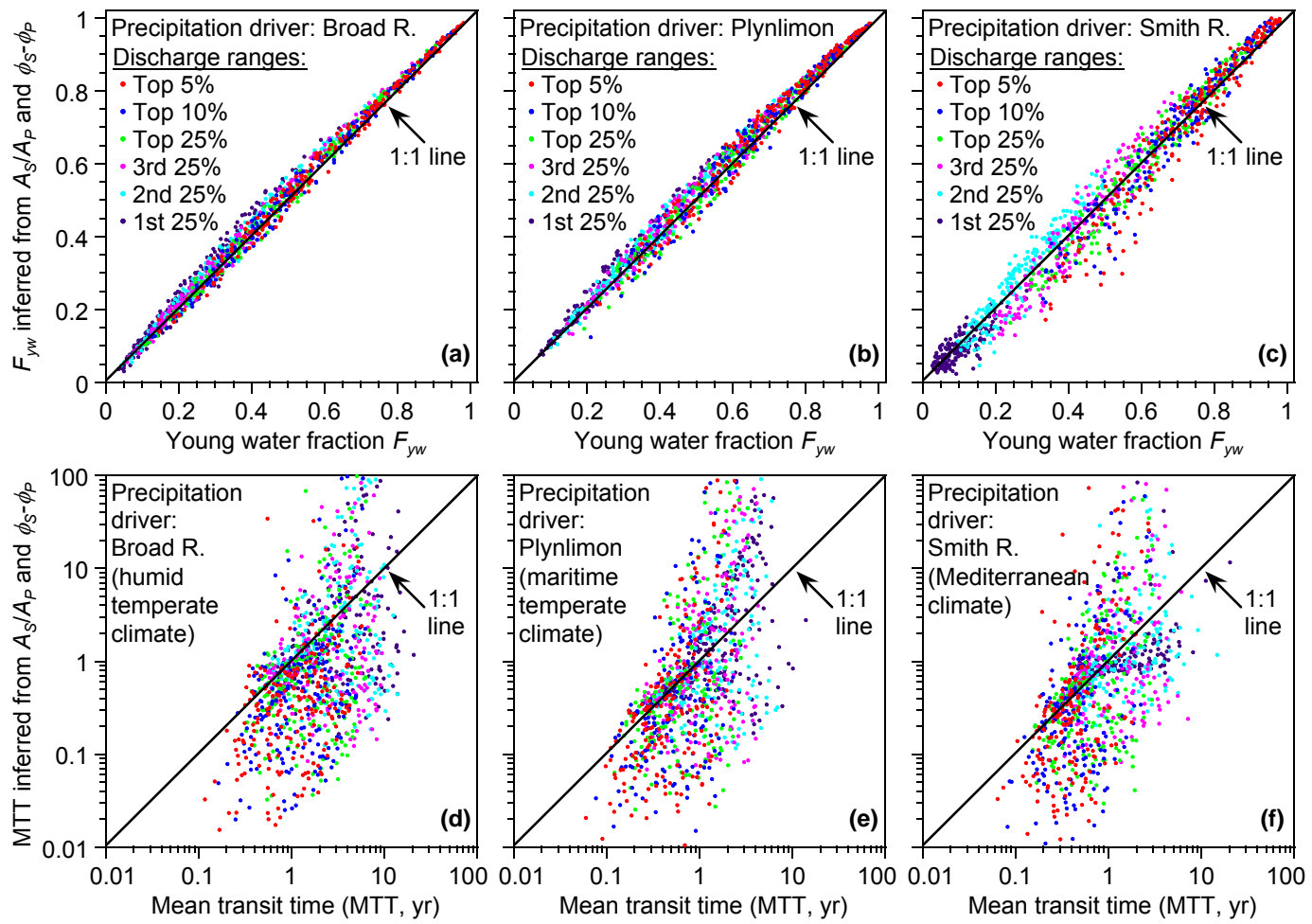

Figure 10. Young water fractions $\left(F_{\mathrm{yw}}\right)$ and MTTs in separate discharge ranges in streamflow from the two-box model. Upper panels compare the time-averaged, flow-specific $F_{\mathrm{yw}}$ for each discharge range (measured by age tracking in the model) with $F_{\mathrm{yw}}$ values estimated from the amplitude ratios $A_{\mathrm{S}} / A_{\mathrm{P}}$ and phase shifts $\varphi_{\mathrm{S}}-\varphi_{\mathrm{P}}$ of the best-fit tracer cycle sinusoids in those discharge ranges (analogously to Fig. 8) using Eqs. (10), (11), (13) and (14) of Paper 1. Similar results (not shown) are also obtained for flow-weighted $F_{\mathrm{yw}}$ and flow-weighted tracer cycle sinusoids. Results obtained from tracer cycle amplitude alone (without phase information) are also similar, except in some cases where the amplitude ratio is small (particularly with Smith River precipitation forcing). Lower panels compare the MTT, determined by age tracking, with the MTT inferred from tracer amplitude ratios and phase shifts using Eqs. (10) and (11) from Paper 1. Each panel shows results from 200 random parameter sets and three contrasting precipitation drivers: Broad River (humid, temperate, with very little seasonality), Plynlimon (wet maritime climate with slight seasonality), and Smith River (Mediterranean climate with pronounced winter-wet, summer-dry seasonality). Tracer cycle amplitudes and phases generally predict the young water fractions in each discharge range, although with some modest scatter. Mean transit-time estimates, by contrast, are highly unreliable, exhibiting large scatter (note log scales).

flected in the correlation between $F_{\mathrm{yw}}$ and the partitioning parameter $\eta$ (Fig. B2). This correlation is not exact, because $F_{\mathrm{yw}}$ will depend not only on how much streamflow comes from the upper box, but also on how much of the upper box is young water. That, in turn, will depend on precipitation climatology and the size of the upper box.

One can use $F_{\mathrm{yw}}$ not only to make comparisons across catchments but also, in an individual catchment, to compare how the proportions of flow traveling by fast flowpaths change across different flow regimes, as shown in Figs. 8-10 and 12. In turn it may be possible to draw inferences about how catchment processes change with flow regime. In this model, variations in $F_{\mathrm{yw}}$ across different flow regimes are strongly correlated with the fractional contributions of the upper box to streamflow (Fig. 13). The slopes and intercepts of the relationships vary among parameter sets, principally reflecting variations in the partitioning parameter $\eta$ and the sizes of the upper and lower boxes. The strong correlations shown in Fig. 13 are typical. Repeating the analysis shown in Fig. 13 for 200 random model "catchments" (i.e., different random parameter sets) yields an average correlation of over 0.99 (again, with different linear relationships for different parameter values). Of course these results - and, more generally, the interpretation of $F_{\mathrm{yw}}$ in terms of upper-box flow - are model-dependent. They are meant to demonstrate only that process inferences can be drawn from $F_{\mathrm{yw}}$, not that these particular inferences should be applied literally to real-world catchments. Indeed one must remember that in the real world there is no "upper box"; it, like all model abstractions, should not be confused with reality.

The young water fraction $F_{\mathrm{yw}}$ may also be helpful in inferring chemical processes from streamflow concentrations of reactive chemical species. Many reactive species exhibit clear concentration-discharge relationships. Because one can determine how $F_{\mathrm{yw}}$ varies, on average, across different ranges of discharge (as demonstrated in Figs. 8-10 
(a)
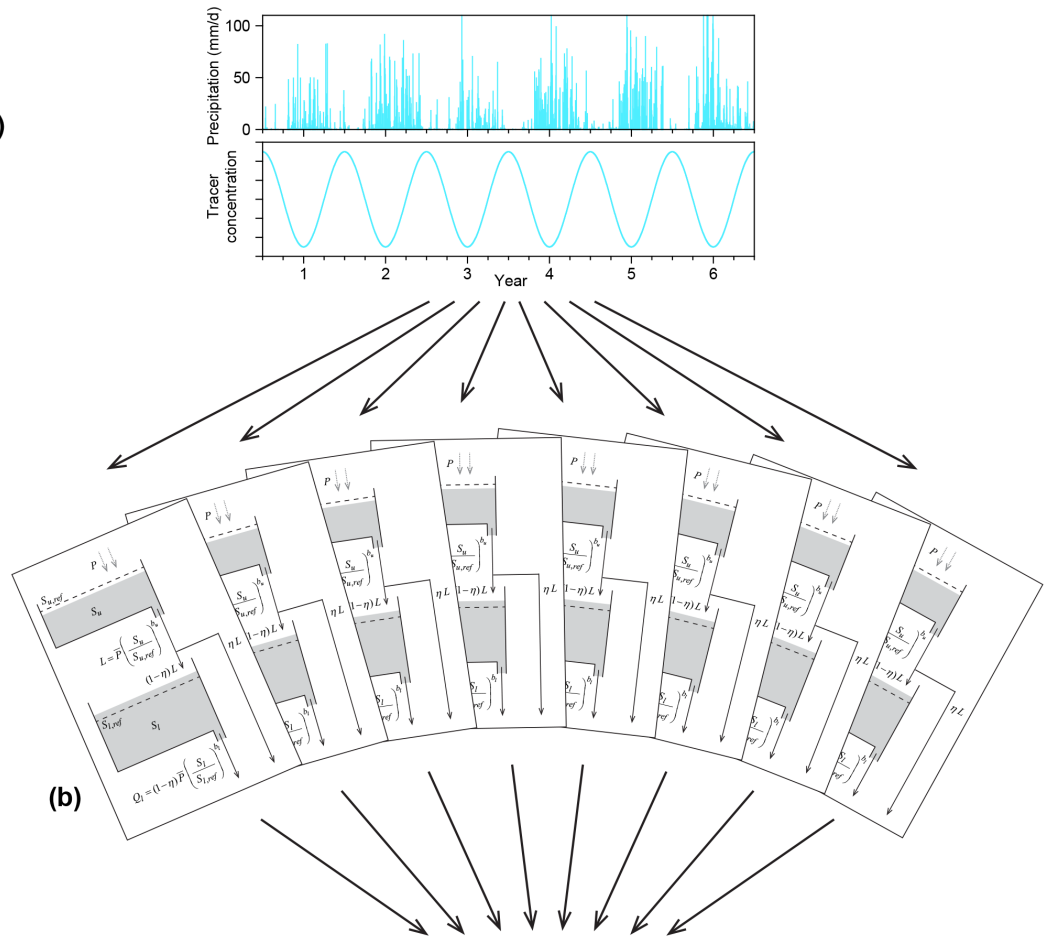

(c)
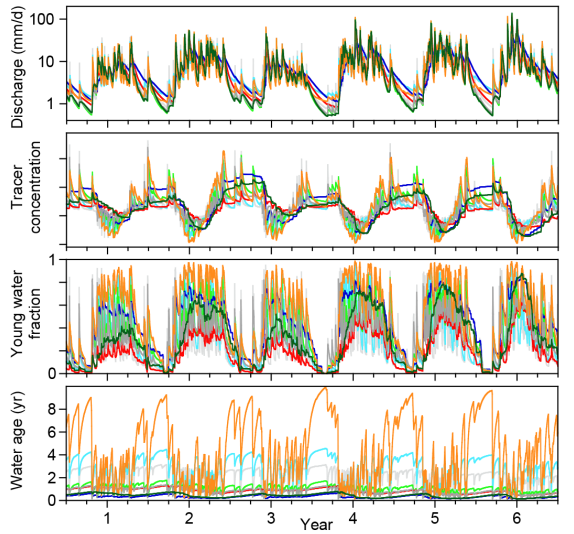

$\downarrow \downarrow \downarrow \downarrow$

(d)
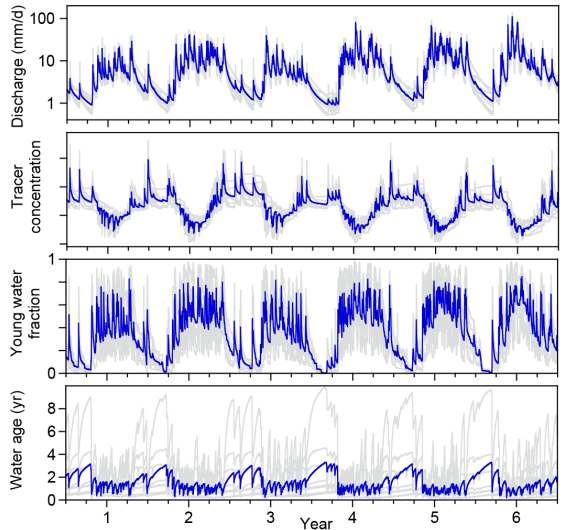

Figure 11. Scheme for simulating spatially heterogeneous catchments with nonstationary tributary subcatchments. A single precipitation time series (a) is used to drive eight copies of the model representing eight tributary streams (b), each with a different set of random parameter values. Streamflows, tracer concentrations, young water fractions, and water ages from these eight nonstationary tributaries (c, with each color representing a separate tributary stream) are mass-averaged to determine the time series that would be observed in the merged streamflow (d, with blue lines showing the merged streamflow and gray lines showing the tributaries). 

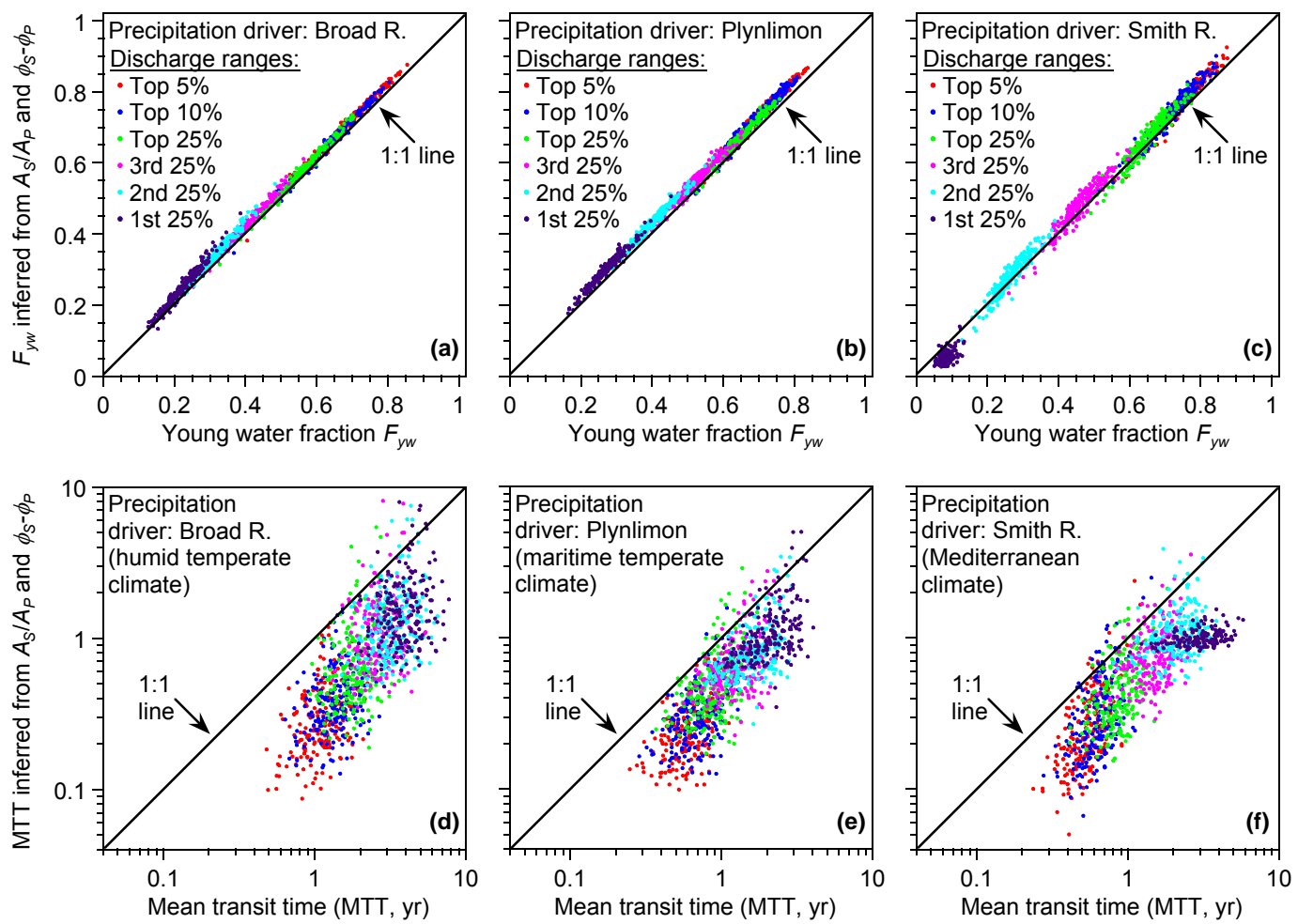

Figure 12. Actual and inferred young water fractions ( $F_{\mathrm{yw}}$, top panels) and MTTs (bottom panels) in separate discharge ranges, under combined effects of nonstationarity and spatial heterogeneity. Panels show results for 200 synthetic catchments, each consisting of eight copies of the two-box model with independent random parameter sets (Fig. 11). Upper panels compare average $F_{\mathrm{yw}}$ values with $F_{\mathrm{yw}}$ values predicted from amplitudes and phases of best-fit tracer cycle sinusoids for each discharge range (e.g., Fig. 8) using Eqs. (10), (11) and (13), (14) of Paper 1. Similar results (not shown) are also obtained for flow-weighted $F_{\mathrm{yw}}$ values and flow-weighted tracer cycle sinusoids. Results obtained from tracer cycle amplitude alone (without phase information) are also similar but exhibit slightly greater bias. Lower panels compare MTT with MTT predicted from tracer amplitude ratios and phase shifts using Eqs. (10) and (11) from Paper 1. Seasonal tracer cycle amplitudes and phases accurately predict young water fractions in separate flow regimes; the corresponding estimates of mean transit times exhibit substantial bias and scatter.

and 12 ), one can potentially construct mixing relationships between $F_{\mathrm{yw}}$ and the concentrations of reactive species. If the measurable range of $F_{\mathrm{yw}}$ is wide enough, one may even be able to estimate the end-member concentrations corresponding to idealized "young water" $\left(F_{\mathrm{yw}}=1\right)$ and "old water" $\left(F_{\mathrm{yw}}=0\right)$.

Figure 14 illustrates a preliminary proof of concept for this approach, based on 20-28 years of weekly precipitation and streamflow samples from three catchments at Plynlimon, Wales (Neal et al., 2011) with contrasting geochemical behavior. I separated the streamflow samples into five discharge ranges (lowest $20 \%$, next $20 \%$, and so on), then fitted the seasonal chloride concentration cycles in each discharge range and calculated the corresponding young water fractions using the approach outlined in Sect. 3.4. I then examined the relationships between these young water fractions and the mean streamwater concentrations of reactive chemical species in each discharge range. Figure 14 shows three different views of how reactive tracer chemistry varies with discharge across the three catchments. The left-hand panels show the average concentrations in each discharge range, as functions of the logarithm of discharge. The middle panels show the same concentrations as functions of the inferred $F_{\mathrm{yw}}$, with the vertical axis at $F_{\mathrm{yw}}=0$ indicating the hypothetical old water end-member. The right-hand panels show the concentrations plotted against the reciprocal of $F_{\mathrm{yw}}$; here, the vertical axis at $1 / F_{\mathrm{yw}}=1$ indicates the hypothetical young water end-member. The gray lines are fitted by hand to indicate general trends, and to suggest potential end-member concentrations.

The three catchments are characterized by contrasts in soil hydrology, with the abundance of impermeable gley soils and boulder clay tills increasing in the rank order Hafren $<$ Hore $<$ Tanllwyth. The same rank order is observed in the calculated young water fractions at high flows, reflecting the greater high-flow variability in chloride concentrations at sites with more impermeable soils. The three sites also exhibit contrasting concentration-discharge relationships for nitrate and aluminum (Fig. 14a, d), two solutes that are relatively abundant in near-surface soil solu- 


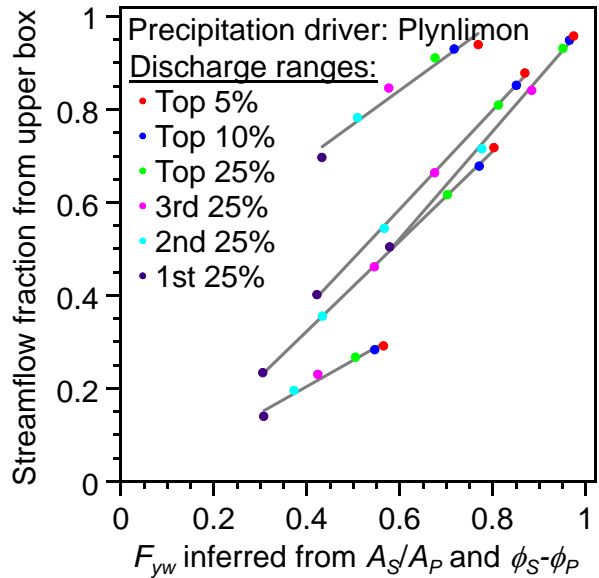

Figure 13. Correlations between flow-weighted young water fractions $F_{\mathrm{yw}}$ and fractional contributions of the upper box to streamflow across different discharge ranges, for five parameter sets illustrating the diversity of relationships that can arise in the model. The upper box contribution is strongly correlated with $F_{\mathrm{yw}}$ in all cases, although the slopes and the intercepts vary among parameter sets.

tions. When plotted against the young water fraction, however, these catchment-specific concentration-discharge relationships collapse to single concentration $-F_{\mathrm{yw}}$ relationships (Fig. 14b, e) in which the three sites are generally indistinguishable within error. These relationships can be extrapolated to reasonably well-constrained old water end-member concentrations of $\sim 0.1 \mathrm{mg} \mathrm{L}^{-1} \mathrm{NO}_{3}-\mathrm{N}$ and $\sim 50 \mu \mathrm{g} \mathrm{L}{ }^{-1} \mathrm{Al}$, and to comparably well-constrained young water end-member concentrations of $\sim 0.45 \mathrm{mg} \mathrm{L}^{-1} \mathrm{NO}_{3}-\mathrm{N}$ and $\sim 600 \mu \mathrm{L} \mathrm{L}^{-1} \mathrm{Al}$ (Fig. 14c, f). In the case of calcium, the three catchments have markedly different concentrationdischarge relationships (Fig. 14g), reflecting differences in the abundance of calcite in their bedrock. As a result, the three catchments have different old water end-member calcium concentrations, ranging from $\sim 1$ to $\sim 4 \mathrm{mg} \mathrm{L}^{-1}$ (Fig. 14h). However, all three streams converge to similar concentrations of $\sim 0.5 \mathrm{mg} \mathrm{L}^{-1} \mathrm{Ca}$ in the young water endmember (Fig. 14i).

It is tempting to interpret the concentration differences between the young and old end-members as reflecting chemical kinetics, but this should be approached with caution. A kinetic interpretation makes sense if the young and old endmembers differ only in age (albeit by an unspecified amount since we cannot know how old the "old" end-member is), but not if they differ in other respects as well. At Plynlimon, for example, porewaters in the acidic soil layers have relatively high concentrations of aluminum and transition metals, and relatively low concentrations of base cations and silica, whereas waters infiltrating deep into the fractured bedrock react with calcite and layer lattice silicates and thus become enriched in base cations and silica, and depleted in aluminum and transition metals (Neal et al., 1997). Thus, one must also consider the alternative hypothesis that the young end-member represents mostly soil water, that the old end-member represents mostly deeper groundwater, and that the two end-members exhibit different chemistry because of their sources rather than their ages. In this case, the endmember compositions identified through plots like Fig. 14 may help in characterizing the chemistries, and thus localizing the physical sources, of the young and old waters. In this proof-of-concept example, all three catchments appear to have geochemically similar young water end-members, with a composition suggesting a shallow soil source, but each has a different old water end-member, suggesting deeper groundwater sources with differing amounts of carbonate minerals. This is consistent with independent geochemical evidence at Plynlimon (Neal et al., 1997).

It is also important to note that if the ideal end-member mixing assumptions hold (i.e., the young and old endmembers are invariant, and the mixture undergoes no further chemical reactions), then the mixing relationships in the middle plots of Fig. 14 should be straight lines, and they should extrapolate to physically realistic (non-negative) concentrations at both $F_{\mathrm{yw}}=0$ and $F_{\mathrm{yw}}=1$. To the extent that the mixing relationships are not straight, or imply unrealistic endmembers, they indicate that these assumptions are not met.

\subsection{General observations and caveats}

It is important to recognize that the inferred young water fractions $F_{\mathrm{yw}}$ plotted in Figs. 7-12 are not in any way calibrated to the true values determined by age tracking. Nor do they make use of any information about the models that transform precipitation into streamflow (neither their structure, nor their parameter values). Thus, there is nothing artifactual about the close correspondence between predicted and observed values of $F_{\mathrm{yw}}$ in Figs. 7-12. Instead, these thought experiments provide strong evidence that seasonal tracer cycles can be used to reliably partition streamflow into young and old fractions ( $F_{\mathrm{yw}}$ and $1-F_{\mathrm{yw}}$, respectively), even in catchments that are both nonstationary and spatially heterogeneous and whose real-world "models" (i.e., whose underlying processes) are poorly understood.

When these results are applied in practice, however, one must keep in mind that in contrast to typical field studies, these thought experiments are based on synthetic data sets that are dense (daily measurements for 10 years) and error-free. Furthermore, these thought experiments use a sinusoidal precipitation tracer signal that varies only seasonally, with no confounding variation on shorter or longer timescales. Further benchmark testing will be needed to test the accuracy of $F_{\mathrm{yw}}$ estimates derived from shorter, sparser, and messier data sets.

One can of course also question the realism of the particular model that I have used for these thought experiments. This model can be calibrated to reproduce the stream discharge with a Nash-Sutcliffe efficiency (NSE) of better than 0.85 

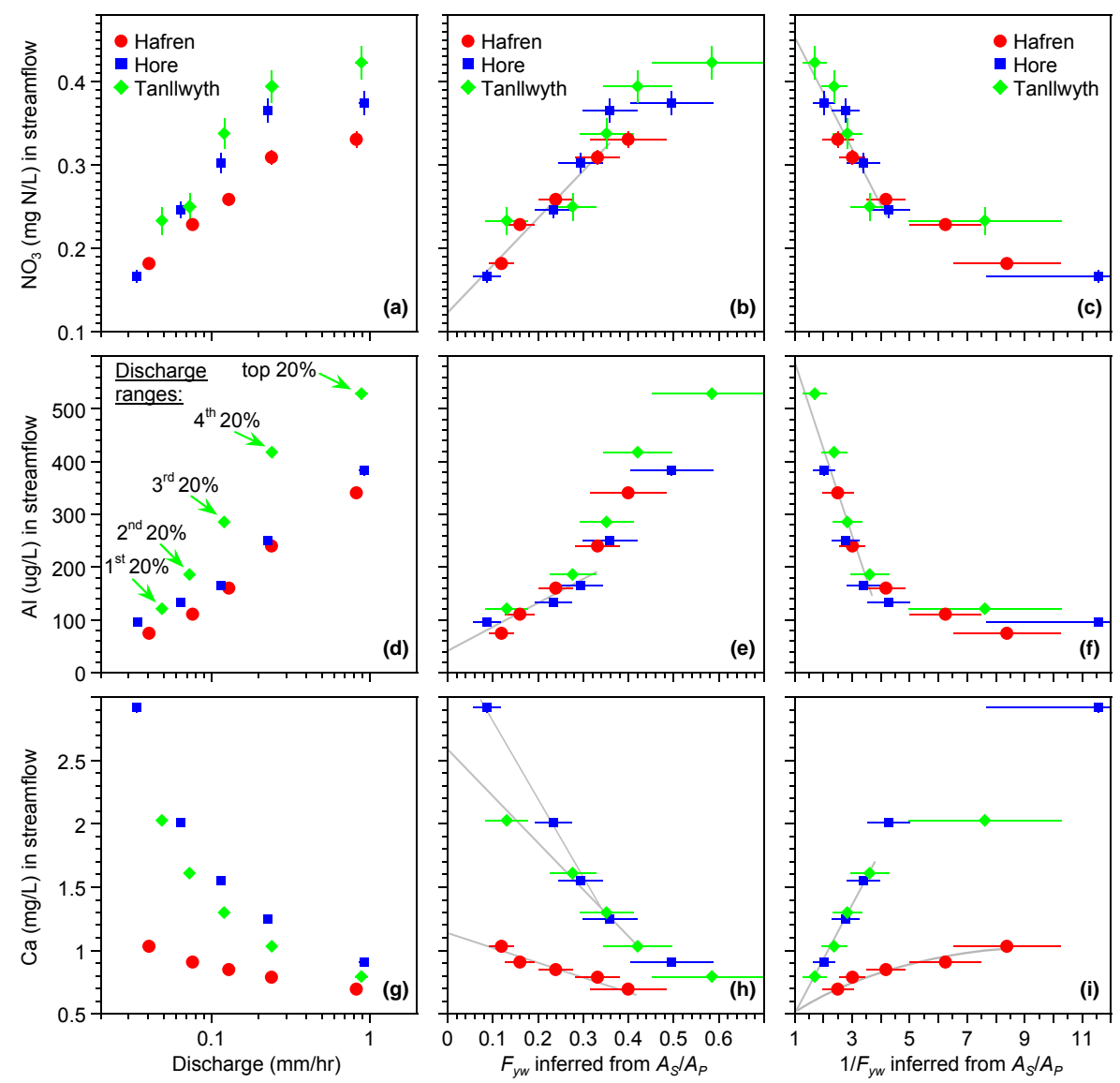

Figure 14. Concentrations of reactive chemical species as functions of discharge (left panels), young water fractions (middle panels), and reciprocal young water fractions (right panels) for streams draining three contrasting catchments at Plynlimon, Wales. Symbols show means for $20 \%$ intervals of each catchment's discharge distribution, and error bars indicate \pm 1 SE (standard error). Gray lines are drawn by hand to indicate general trends. Concentration-discharge relationships in nitrate and aluminum differ among the three catchments (a, d) but collapse to single concentration- $F_{\mathrm{yw}}$ relationships $(\mathbf{b}-\mathbf{c}, \mathbf{e}-\mathbf{f})$. These concentration- $F_{\mathrm{yw}}$ relationships extrapolate to broadly consistent old water endmembers $\left(F_{\mathrm{yw}}=0, \mathbf{b}\right.$ and $\left.\mathbf{e}\right)$ and young water end-members $\left(F_{\mathrm{yw}}=1, \mathbf{d}\right.$ and $\left.\mathbf{f}\right)$. Calcium follows different concentration- $F_{\mathrm{yw}}$ relationships in the three streams, which extrapolate to three different old water end-members (h) but roughly the same young water end-members (i).

at two of the three sites, but there is no guarantee that it is getting the right answer for the right reasons. All models - whether lumped conceptual models or "physically based" spatially explicit models - necessarily involve approximations and simplifications. In plain language: any model, including this one, incorporates assumptions that are false and are known to be false. One obvious idealization (a less euphemistic word would be fiction) is the use of well-mixed boxes as the core of most lumped conceptual models, including the model presented here. Assuming that everything in each box is completely mixed or, equivalently, that it is randomly sampled in the outflow - regardless of where it is physically located in the landscape - clearly strains credibility, but this is what typical conceptual models must assume for mathematical convenience. The model presented here is no different.

What is different, however, is that here the model is used for purposes that make its literal realism unnecessary. Typi- cal modeling studies draw conclusions about real-world systems from model behavior; thus, those conclusions depend critically on the realism of the model. Here, the primary goal is not to test how catchments work but instead to test specific methods for inferring water ages from complex, nonstationary time series of tracer concentrations. All the model must do is generate outputs with reasonable degrees of complexity and nonstationarity; it is not essential that the model generates these time series by the same mechanisms that realworld catchments do. The only inductive leap is the inference that if a method correctly infers water ages from tracer patterns in these complex, nonstationary time series, it will also correctly infer water ages in complex, nonstationary time series generated by real-world catchments.

It is important to highlight an essential difference between the approach developed here and typical studies that infer water ages or transit-time distributions from calibrated models (e.g., Birkel et al., 2011; Van der Velde et al., 2012; Hei- 
dbüchel et al., 2012; Hrachowitz et al., 2013; Benettin et al., 2013, 2015). When one draws inferences from a model, their validity depends on whether that model is structurally adequate and whether its parameter values are realistic, both of which are usually in doubt. Here, by contrast, I have developed an inferential method (for estimating the young water fraction $F_{\mathrm{yw}}$ from seasonal tracer cycles) that is not drawn from - and thus does not depend on - the model's structure or its parameter values. The model is used only to create synthetic data to test the inferential method.

The results reported here, together with those in Paper 1, show that MTTs cannot be estimated reliably by fitting sine waves to seasonal tracer cycles from nonstationary or spatially heterogeneous catchments. These results do not imply that other methods for estimating MTTs are any better; instead, they imply only that sine wave fitting has been subjected to rigorous benchmark testing and has failed. The other methods have not yet been similarly tested, and it is unclear whether they too will fail. Efforts to fill this knowledge gap are underway. But in the meantime, ignorance is not bliss; one should not simply assume that these other methods work as intended, just because they have not yet been rigorously tested. In that regard, the most general contribution of this analysis is not that it reveals specific problems with MTT estimation from seasonal tracer cycles, or that it demonstrates the reliability of $F_{\mathrm{yw}}$ as an alternative metric of catchment transit times, but rather that it illustrates the clarifying power of well-designed benchmark tests.

\section{Summary and conclusions}

The age of streamflow - i.e., the time that has elapsed since it fell as precipitation - is an essential descriptor of catchment functioning with broad implications for runoff generation, contaminant transport, and biogeochemical cycling (Kirchner et al., 2000; McGuire and McDonnell, 2006). The age of streamflow is commonly measured by its MTT, which in turn has often been estimated from the damping of seasonal cycles of chemical and isotopic tracers (such as $\mathrm{Cl}^{-}, \delta^{18} \mathrm{O}$, or $\delta^{2} \mathrm{H}$ ). In a companion paper (Paper 1: Kirchner, 2016), I demonstrated that MTT cannot be reliably estimated from seasonal tracer cycles in spatially heterogeneous catchments, and I proposed an alternative water age metric, the young water fraction $F_{\mathrm{yw}}$, which is relatively immune to the errors and biases that afflict the MTT.

Here I have explored how catchment nonstationarity affects estimates of MTT and $F_{\text {yw }}$, using simple thought experiments based on a simple two-box conceptual model (Fig. 1) driven by three precipitation time series representing a range of precipitation climatologies (Fig. 2). The model exhibits complex nonstationary behavior (Fig. 3), with striking volatility in tracer concentrations, young water fractions, and mean transit times as the mixing ratio between the upper and lower boxes shifts in response to precipitation events. This mixing ratio is both hysteretic and nonstationary, varying in response both to precipitation forcing and to the antecedent moisture status of the two boxes (Fig. 4).

Marginal (time-averaged) age distributions in drainage are skewed toward younger ages than the storage distributions they come from, because storage is flushed more quickly (and thus is younger) during periods of higher discharge (Fig. 5). The age distributions in whole-catchment storage and discharge are approximate power laws, with markedly different slopes (Fig. 5). The age distribution in streamflow becomes increasingly skewed at higher discharges, with a marked increase in the young water fraction and decrease in the mean water age (Fig. 6), reflecting the increased dominance of the upper box at higher flows. Flow-weighted average MTTs are typically close to the steady-state MTT, estimated as the ratio of the total storage to the throughput rate. However, the marginal age distributions are markedly different from the distributions that would be expected in steady state, demonstrating that steady-state approximations are misleading guides to the non-steady-state behavior of the system, even on average.

Even this simple two-box model exhibits strong equifinality (Fig. B1), with four of its five parameters having virtually no identifiability through hydrograph calibration. However, scaling arguments based on simple perturbation analyses (Sect. 3.2) reveal ratios of parameters that can be constrained through hydrograph calibration (Fig. B2), greatly reducing the equifinality in the parameter space. Unfortunately, water age is primarily controlled by residual storage, which cannot be constrained through hydrograph calibration (Fig. B2). Thus, parameter sets that yield virtually identical hydrographs imply widely differing young water fractions and mean water ages (Fig. B3).

The simple two-box model was used to simulate discharge, water ages, and the propagation of seasonal tracer cycles through the catchment, across wide ranges of random parameter sets. MTTs inferred from the damping and phase shift of the seasonal tracer cycles exhibited strong underestimation bias and large scatter (Fig. 7). This result implies that many literature MTT values (and thus also residual storage volumes) may have been underestimated by large factors. By contrast, the seasonal tracer cycles accurately predicted the actual $F_{\mathrm{yw}}$ in streamflow, as determined by age tracking within the model (Fig. 7).

Flow-weighted fits to the seasonal tracer cycles accurately predicted the flow-weighted average $F_{\mathrm{yw}}$ in streamflow, while unweighted fits to the seasonal tracer cycles accurately predicted the unweighted average $F_{\mathrm{yw}}$. The streamflow time series can be separated into distinct flow regimes with their own seasonal tracer cycles (Fig. 8), which accurately reflect the $F_{\mathrm{yw}}$ in each flow regime (Figs. 9, 10). Seasonal tracer cycles also accurately predicted the $F_{\mathrm{yw}}$ in the merged streamflow from spatially heterogeneous assemblages of nonstationary model catchments (Fig. 12). Impor- 
tantly, all of these $F_{\mathrm{yw}}$ predictions were really predictions; they were not calibrated in any way.

The relationship between $F_{\mathrm{yw}}$ and the flow regime reflects how the fluxes from short-term storages vary with hydrologic forcing (Fig. 13). In a preliminary proof of concept (Fig. 14), I showed that one can construct mixing relationships between solute concentrations and $F_{\mathrm{yw}}$ values for discrete flow regimes. From these mixing relationships one can estimate the chemical composition of idealized "young water" and "old water" end-members (Fig. 14).
These findings extend the results of Paper 1 by showing that estimates of MTT from seasonal tracer cycles are unreliable under nonstationarity as well as spatial heterogeneity. These findings also extend the results of Paper 1 by showing that $F_{\mathrm{yw}}$ can be reliably estimated in nonstationary catchments as well as spatially heterogeneous ones, and it can also be reliably estimated for discrete flow regimes. These results further demonstrate that $F_{\mathrm{yw}}$ can be reliably estimated for discrete flow regimes and can provide helpful insights into the hydrological and hydrochemical functioning of catchments. Most generally, these results, along with those of Paper 1, illustrate how well-posed benchmark tests can be essential in clarifying what is knowable - and, conversely, unknowable - in environmental research. 


\section{Appendix A: Solution scheme}

For simplicity and efficiency, the hydrological model is solved on a fixed daily time step. This requires some care with the numerics, given the clear (though often overlooked) dangers in naive forward-stepping simulations of nonlinear equations (Clark and Kavetski, 2010; Kavetski and Clark, 2010, 2011). Here I use a weighted combination of the trapezoidal method (which is partly implicit, for enhanced accuracy) and the backward Euler method (which is fully implicit, for guaranteed stability). The hydrological solution scheme is illustrated here for the upper box; the lower box is handled analogously. The storage in the upper box is updated using the following equation:

$$
\begin{aligned}
S_{\mathrm{u}}\left(t_{i+1}\right) & -S_{\mathrm{u}}\left(t_{i}\right)=\Delta t\left(P-\rho k_{\mathrm{u}} S_{\mathrm{u}}\left(t_{i+1}\right)^{b_{\mathrm{u}}}\right. \\
& \left.-(1-\rho) k_{\mathrm{u}} S_{\mathrm{u}}\left(t_{i}\right)^{b_{\mathrm{u}}}\right),
\end{aligned}
$$

where $S_{\mathrm{u}}\left(t_{i}\right)$ is the storage in the upper box at the beginning of the $i$ th time interval (with length $\Delta t$ ), $S_{\mathrm{u}}\left(t_{i+1}\right)$ is the storage at the end of that interval (and thus the beginning of the next), and $P$ is the average precipitation rate over the interval. Equation (A1) is implicit and nonlinear; there is no closed-form solution for the future storage $S_{\mathrm{u}}\left(t_{i+1}\right)$, which instead is found using Newton's method. The relative dominance of the trapezoidal and backward Euler solutions is determined by the weighting factor $\rho$, which takes on values between $\rho=0.5$ (trapezoidal method) and $\rho=1$ (backward Euler method). The value of $\rho$ in Eq. (A1) is determined for each time step using the simple stability criterion:

$\rho=\min \left(0.5+0.5 \frac{\left(P-k_{\mathrm{u}} S_{\mathrm{u}}\left(t_{i}\right)^{b_{\mathrm{u}}}\right) \Delta t}{\left(P / k_{\mathrm{u}}\right)^{1 / b_{\mathrm{u}}}-S_{\mathrm{u}}\left(t_{i}\right)}, \quad 1\right)$,

where the numerator represents the amount that $S_{\mathrm{u}}$ would change during one time step if the instantaneous drainage rate $L$ in Eq. (1) were projected forward in time, and the denominator represents the difference between $S_{\mathrm{u}}$ 's current value and its equilibrium value at the precipitation rate $P$. Equation (A2) says that if the trapezoidal method would move $S_{\mathrm{u}}$ by only a small fraction of the distance to its equilibrium value (at the precipitation rate $P$ ), then the stability advantages of the backward Euler method are unnecessary and the more accurate trapezoidal method should dominate the solution instead $(\rho \approx 0.5)$. On the other hand, if the trapezoidal method would overshoot the equilibrium value, then $\rho=1$ and the fully implicit backward Euler method is used to solve Eq. (A1). The closer the trapezoidal method would come to overshooting the equilibrium, the larger the value of $\rho$ and the greater the weight that is given to the backward Euler solution. The guaranteed stability of the backward Euler method is important when $b_{\mathrm{u}}$ or $b_{1}$ is large, because the underlying equations can become quite stiff. After the final value of $S_{\mathrm{u}}$ is determined by Eq. (A1), the drainage from $S_{\mathrm{u}}$ between $t_{i}$ and $t_{i+1}$ is determined by mass balance:
$L=P+\left(S_{\mathrm{u}}\left(t_{i}\right)-S_{\mathrm{u}}\left(t_{i+1}\right)\right) / \Delta t$,

where $L$ is the average drainage rate over the interval $\Delta t$ between $t_{i}$ and $t_{i+1}$.

The tracer concentrations are determined under the assumption that each box is well mixed, implying that individual water parcels within each box do not need to be tracked, and also that the concentration draining from each box equals the average concentration within the box. I make the simplifying assumption that each box's inflow and outflow rates (and also inflow concentrations) are constant over each day. Again taking the upper box as an example, these assumptions imply that starting from $t=t_{i}$ the tracer concentration will evolve as

$\frac{\mathrm{d} C_{\mathrm{u}}}{\mathrm{d} t}=\frac{P\left(C_{\mathrm{P}}-C_{\mathrm{u}}\right)}{S_{\mathrm{u}}\left(t_{i}\right)+(P-L)\left(t-t_{i}\right)}$,

where $C_{\mathrm{P}}$ and $C_{\mathrm{u}}$ are the concentrations in precipitation and the upper box, respectively, and the denominator expresses how the volume in the box changes with time from its initial value of $S_{\mathrm{u}}\left(t_{i}\right)$. Integrating Eq. (A4) over an interval $\Delta t$ yields the concentration updating formula:

$C_{\mathrm{u}}\left(t_{i+1}\right)=C_{\mathrm{P}}+\left(C_{\mathrm{u}}\left(t_{i}\right)-C_{\mathrm{P}}\right)\left(\frac{S_{\mathrm{u}}\left(t_{i}\right)}{S_{\mathrm{u}}\left(t_{i+1}\right)}\right)^{(P /(P-L))}$,

where any quantities that are not shown as functions of time are constant at their average values over the interval. Equation (A5) could potentially become difficult to compute when $P$ and $L$ are nearly equal (differing by, say, less than 1 part in 1000), and the power function approaches its exponential limit. In such cases the change in volume in Eq. (A4) becomes trivially small, and one can replace Eq. (A5) with the more familiar exponential formula for a well-mixed box of constant volume:

$C_{\mathrm{u}}\left(t_{i+1}\right)=C_{\mathrm{P}}+\left(C_{\mathrm{u}}\left(t_{i}\right)-C_{\mathrm{P}}\right) \exp \left(-P \Delta t / S_{\mathrm{u}}\right)$.

After the tracer concentrations are updated, the average concentrations in drainage are calculated by mass balance, as follows:

$C_{\mathrm{L}}=\left[C_{\mathrm{P}}\left(t_{i}\right) P+C_{\mathrm{u}}\left(t_{i}\right) S_{\mathrm{u}}\left(t_{i}\right)-C_{\mathrm{u}}\left(t_{i+1}\right) S_{\mathrm{u}}\left(t_{i+1}\right)\right] / L$,

where $C_{\mathrm{L}}$ is the average concentration in drainage over the time interval between $t_{i}$ and $t_{i+1}$.

The mean age within each box is modeled analogously to the tracer concentrations, following the "age mass" concept widely used in groundwater hydrology. Here I will illustrate the approach using the example of the lower box, since it is the more complex case (for the upper box, the input age in precipitation is zero, but this is not true for the upper-box drainage that recharges the lower box). Assuming that the inflow and outflow rates $L(1-\eta)$ and $Q_{1}$ are constant over a day, as is the average age $\bar{\tau}_{\mathrm{L}}$ of the inflow from the upper 
box, the mean age in the lower box should evolve according to

$$
\frac{\mathrm{d} \bar{\tau}_{1}}{\mathrm{~d} t}=\frac{L(1-\eta)\left(\bar{\tau}_{\mathrm{L}}-\bar{\tau}_{1}\right)}{S_{1}\left(t_{i}\right)+\left(L(1-\eta)-Q_{1}\right)\left(t-t_{i}\right)}+1
$$

which is directly analogous to Eq. (A4), except for the additional term of +1 , which accounts for the continual aging of the water in the box. The solution to Eq. (A8) is

$$
\begin{aligned}
\bar{\tau}_{1}\left(t_{i+1}\right) & =\bar{\tau}_{\mathrm{L}}+\frac{S_{1}\left(t_{i+1}\right)}{2 L(1-\eta)-Q_{1}}+\left(\bar{\tau}_{1}\left(t_{i}\right)\right. \\
-\bar{\tau}_{\mathrm{L}} & \left.-\frac{S_{1}\left(t_{i}\right)}{2 L(1-\eta)-Q_{1}}\right)\left(\frac{S_{1}\left(t_{i}\right)}{S_{1}\left(t_{i+1}\right)}\right)^{\left(\frac{L(1-\eta)}{L(1-\eta)-Q_{1}}\right)},
\end{aligned}
$$

where $\bar{\tau}_{1}\left(t_{i}\right)$ and $\bar{\tau}_{1}\left(t_{i+1}\right)$ are the mean age of the water in the lower box at the beginning and end of the time interval. Analogously to tracer concentrations, one can calculate the mean age of the drainage from the box based on the inputs and the change in mean age inside the box, using conservation of "age mass":

$$
\begin{aligned}
\bar{\tau}_{Q_{1}} & =\left[\bar{\tau}_{\mathrm{L}}\left(t_{i}\right)(1-\eta)+\bar{\tau}_{1}\left(t_{i}\right) S_{1}\left(t_{i}\right)\right. \\
& \left.-\left(\bar{\tau}_{1}\left(t_{i+1}\right)-\Delta t\right) S_{1}\left(t_{i+1}\right)\right] / Q_{1},
\end{aligned}
$$

where the factor of $-\Delta t$ accounts for the aging of the contents of the box.

The approach used here for concentrations and water ages requires the assumption that input fluxes to each box are constant within each time interval (but constant at their average values, not their initial values). This is a reasonable approximation, particularly when we have no sub-daily precipitation data. And in exchange for this simplifying assumption, Eqs. (A5), (A6), and (A9) provide something important, namely, the exact analytical solution for the evolution of concentration and age during each time interval. Thus, these equations directly solve for the correct result even if, for example, an individual day's rainfall is much greater than the total volume of the upper box. The equations above will correctly calculate the consequences of the (potentially many-fold) flushing that occurs in such cases. The approach outlined above also guarantees exact consistency between stocks and fluxes (but note that this is not done in the usual way by updating stocks with fluxes, but rather by calculating output fluxes from inputs and changes in stocks). Readers should keep in mind that all stocks and properties of stocks (i.e., storage volumes, concentrations, and ages) are expressed as the instantaneous values at the beginning of each time interval, and that fluxes and properties of fluxes (i.e., water fluxes and their concentrations and ages) are expressed as averages over each time interval. Otherwise it could be difficult to make sense of the equations above.

\section{Appendix B: Equifinality in hydraulic behavior and divergence in travel times}

The analysis outlined in Sect. 3.2 implies that approximate equifinality is inevitable, even in such a simple model, because variations in the exponents $b_{\mathrm{u}}$ and $b_{1}$ and the reference storage levels $S_{\mathrm{u}, \text { ref }}$ and $S_{\mathrm{l} \text {,ref }}$ will have nearly offsetting effects on the model's runoff response. Equations (10) and (11) show that, for a given average precipitation forcing, any parameter values for which the partitioning coefficient $\eta$ and the ratios $S_{\mathrm{u}, \mathrm{ref}} / b_{\mathrm{u}}$ and $S_{1, \text { ref }} /\left[(1-\eta) b_{1}\right]$ are invariant would give nearly equivalent hydrograph predictions, because the hydraulic response timescales of the upper and lower boxes, and their relative contributions to discharge, would be invariant. These conditions can be achieved for widely varying values of the individual parameters $b_{\mathrm{u}}, b_{\mathrm{l}}, S_{\mathrm{u}, \text { ref }}$, and $S_{\mathrm{l}, \text { ref }}$.

This equifinality problem can be readily visualized by plots like Fig. B1. To generate Fig. B1, I ran the model with Smith River precipitation forcing and the reference parameter set (shown by the red squares in Fig. B1) and used the resulting daily hydrograph (after the spin-up period) as virtual "ground truth" for model calibration. I then ran the model with 1000 random parameter sets and used the NSE of the logarithms of discharge to measure how well their hydrographs matched the reference hydrograph (thus the reference hydrograph has a NSE of 1 by definition). The 50 best-fitting parameter sets, all with NSE $\geq 0.98$, are shown as dark blue points in Fig. B1. The bottom row of scatterplots shows the conventional "dotty plots". Their flat tops are the hallmark of equifinality, i.e., wide ranges of parameter values give equally good hydrograph predictions (Beven, 2006). Only the partition coefficient $\eta$, which performs well across half its range, can be even modestly constrained by calibration. (The other precipitation drivers yield results similar to those shown in Fig. B1.)

The other panels of the scatterplot matrix also give important clues to the origins of the observed equifinality. In particular, the best-fitting parameter sets show strong correlations between $S_{\mathrm{u}, \text { ref }}$ and $b_{\mathrm{u}}$, and between $S_{1, \text { ref }}$ and $b_{1}$, as expected from the perturbation analysis presented in Sect. 3.2. Thus, good model performance can be obtained across almost the entire range of these parameters but only for specific parameter combinations. These parameter combinations correspond to "valleys" in the model's response surface, a longstanding problem in model calibration (e.g., Ibbitt and O'Donnell, 1974). The interdependence of the parameters is visually obvious in the scatterplot matrix but is invisible in the conventional "dotty plots".

This information can be exploited to design parameter spaces that are more identifiable through calibration (e.g., Ibbitt and O'Donnell, 1974). An ideal parameter space would be one in which (1) all parameters are highly identifiable, meaning the goodness-of-fit surface is strongly curved along each parameter axis, and (2), in the best-fitting parameter sets, no parameters are strongly correlated with one another. 


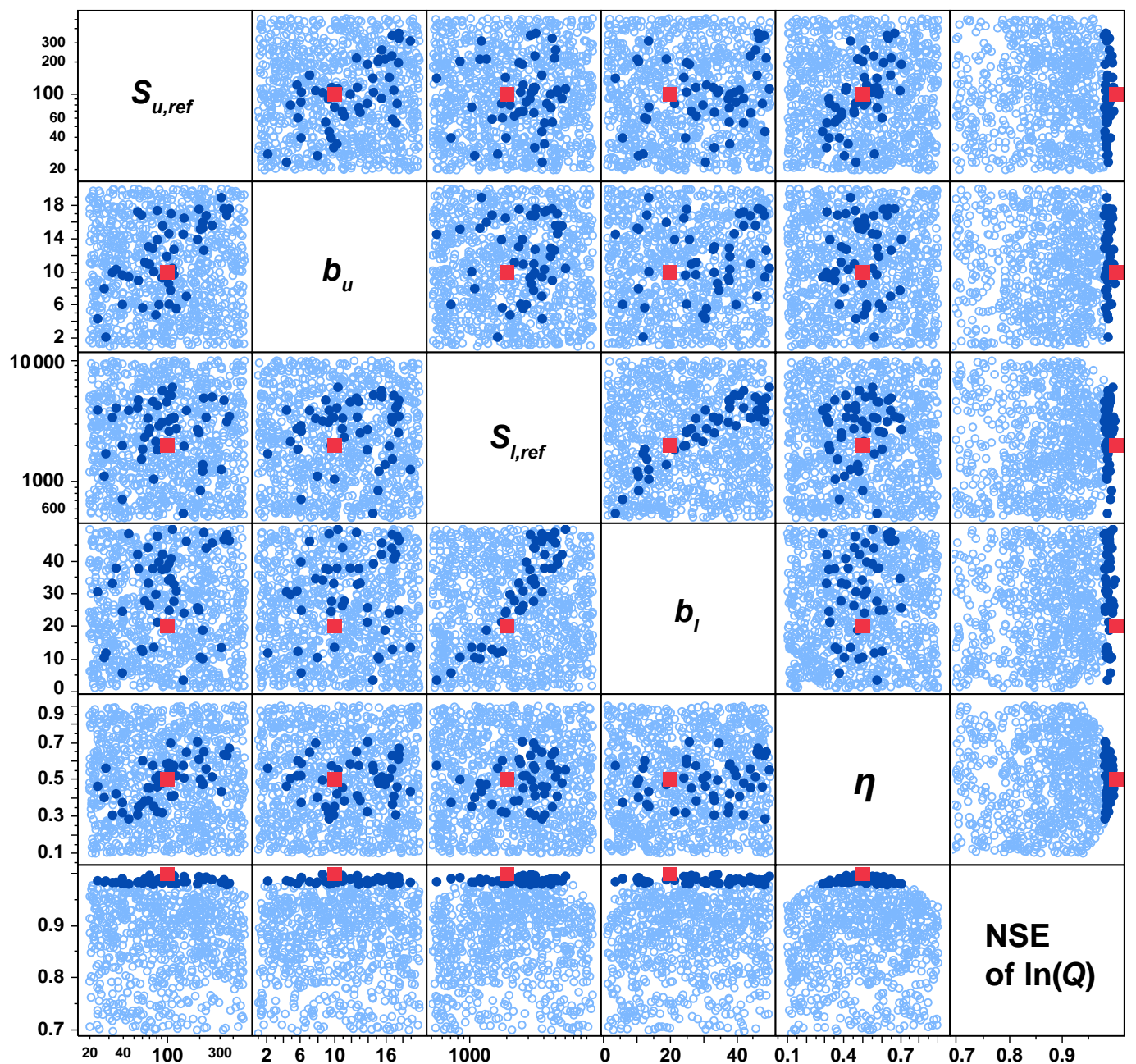

Figure B1. Equifinality in discharge predictions. The scatterplot matrix shows relationships among 1000 random parameter sets and the Nash-Sutcliffe efficiency (NSE) of discharge time series driven by Smith River (Mediterranean climate) precipitation forcing. The red square indicates the "reference" parameter set that was used to generate the discharge time series that the other parameter sets were tested against; these reference parameters thus correspond to NSE $=1.00$ by definition. The dark blue dots show the best-fitting 50 (or $5 \%$ ) of the parameter sets, all with NSE $\geq 0.98$. Excellent discharge predictions can be obtained across almost the full range of all five model parameters, except the partition coefficient $\eta$, which performs well across only about half its range. The dark blue dots show clear correlations between the reference storage levels in each box $\left(S_{\mathrm{u}, \mathrm{ref}}, S_{\mathrm{l}, \mathrm{ref}}\right)$ and the corresponding drainage function exponents $\left(b_{\mathrm{u}}, b_{1}\right)$; these correlations delimit regions with nearly constant hydraulic response timescales, as defined by Eqs. (10) and (11).

The second of these criteria is necessary (although not sufficient) for the first, as Fig. B1 illustrates. A third criterion is that all parameters that are needed for simulating any quantities of interest must be determined somehow within the parameter space, either individually or through combinations of other parameters. Thus, for example, although the volumes of the boxes $\left(S_{\mathrm{u}, \mathrm{ref}}\right.$ and $\left.S_{1, \mathrm{ref}}\right)$ are strongly correlated with their exponents $\left(b_{\mathrm{u}}\right.$ and $\left.b_{1}\right)$, the parameter space must allow them to be individually determined, because as Eqs. (12)-(14) suggest, the mean transit times will be controlled primarily by the volumes alone (not in combination with the exponents), whereas the runoff response will be controlled primarily by the ratios of volumes to exponents (Eqs. 10,11). These crite- ria, plus some trial and error, lead to a more identifiable parameter space, whose five axes are $S_{\mathrm{u}, \text { ref }}, S_{1, \text { ref }}, S_{\mathrm{u}, \text { ref }} /\left(\eta \cdot b_{\mathrm{u}}\right)$, $S_{1, \text { ref }} / b_{1}$, and $\eta$.

Figure B2 shows that this parameter space exhibits much less equifinality than the parameter space shown in Fig. B1, although the underlying parameter sets and model simulations are exactly the same. All that has been done is to reproject the parameter space onto a different set of coordinate axes in which the curvature of the goodness-of-fit surface is more clearly visible. Thus, much of the apparent equifinality in the parameter space has been eliminated by simple transformations of variables. These transformations can be designed by eye in this case, because the dimensionality of 

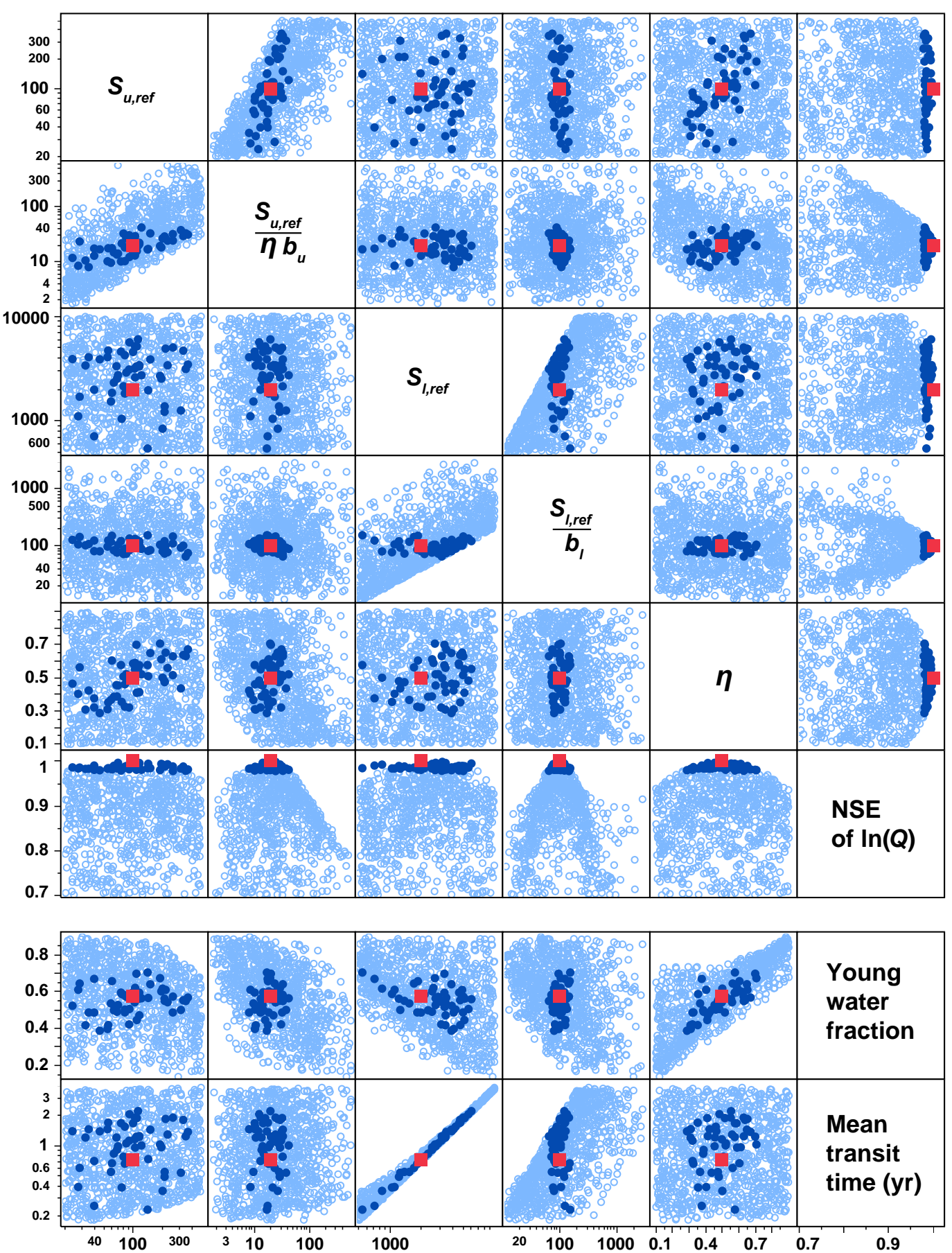

Figure B2. Equifinality partly cured by parameter transformations. The scatterplot matrix shows relationships among 1000 random parameter sets and the NSE of discharge time series driven by Smith River (Mediterranean climate) precipitation forcing, along with two key model outputs, the young water fraction and mean transit time in discharge (bottom two rows). As in Fig. B1, the red square indicates the "reference" parameter set that was used to generate the discharge time series that the other parameter sets were tested against; these reference parameters thus correspond to NSE $=1.00$ by definition. The dark blue dots show the best-fitting 50 (or $5 \%$ ) of the parameter sets, all with NSE $\geq 0.98$. In contrast to Fig. B1, three of the five parameters can be constrained by calibration against discharge (as shown by the clear peaks in NSE), and none of the parameters are strongly correlated with one another. However, the two reference storage volumes $S_{\mathrm{u}, \text { ref }}$ and $S_{1, \text { ref }}$ remain poorly constrained. The mean transit time is determined almost entirely by $S_{1, \text { ref }}$, so it cannot be constrained by parameter calibration against the streamflow hydrograph. 

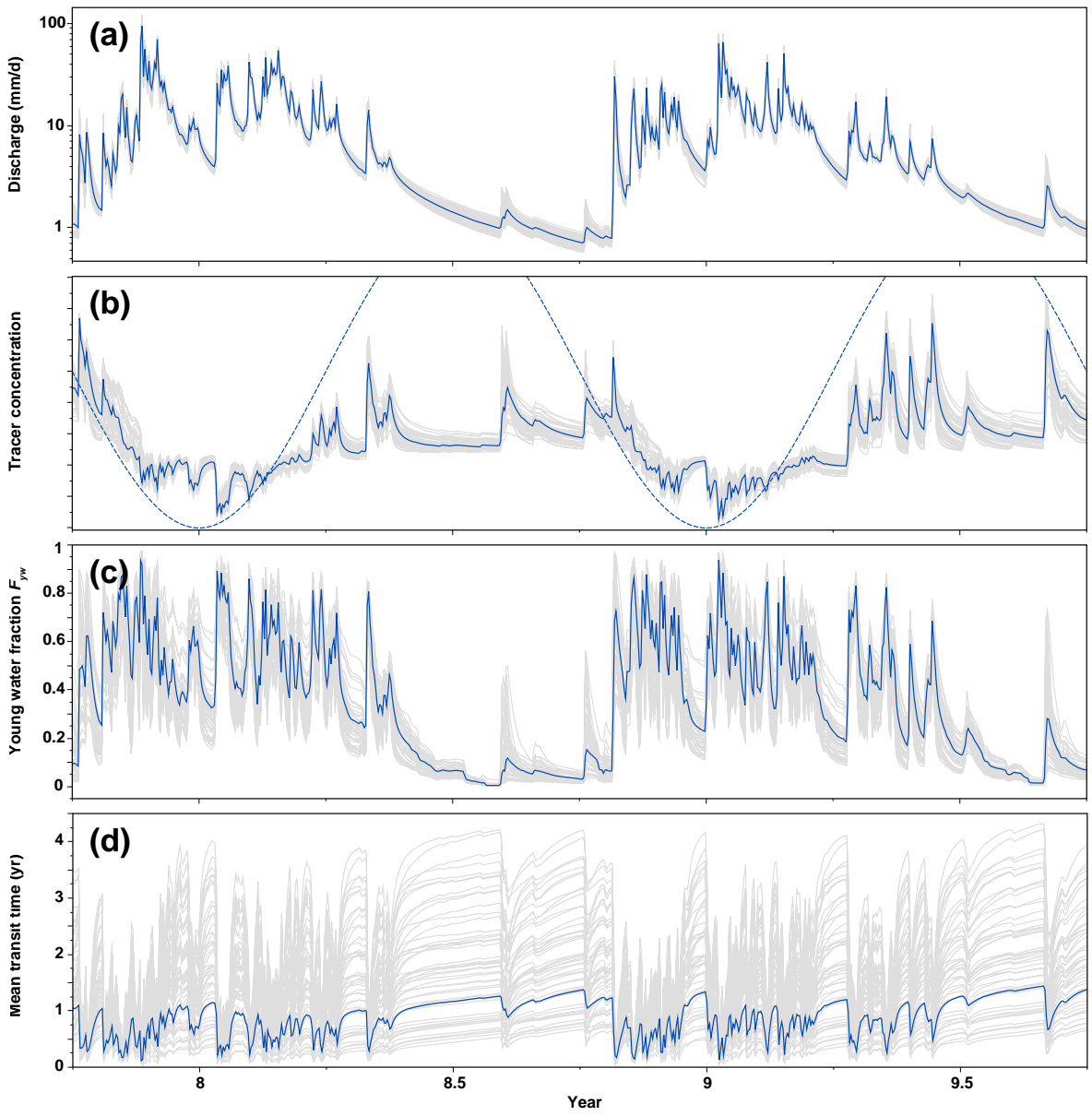

Figure B3. Excerpts from time series of discharge, tracer concentrations, young water fractions, and mean travel times in the two-box model with Smith River (Mediterranean climate) precipitation forcing and the reference parameter set (the dark lines, for the parameter values shown by the red squares in Figs. B1 and B2) and the 50 parameter sets that come closest to matching the reference discharge time series (the light gray lines, for the parameter sets shown by the solid blue dots in Figs. B1 and B2). The 50 gray hydrographs (a) cluster closely around the blue hydrograph (which is unsurprising because they have been selected to do so). The 50 gray tracer concentration curves (b) also generally follow the blue curve (the precipitation tracer sinusoid is shown for comparison by the dashed line). By contrast, the young water fraction $F_{\mathrm{yw}}(\mathbf{c})$ and mean transit time $(\mathbf{d})$ are much more variable; the gray curves vary by an average range of 0.3 in $F_{\mathrm{yw}}$ and a factor of 9.5 in mean transit time.

the original parameter space is low. In higher-dimension parameter spaces, multivariate techniques such as factor analysis may be helpful. Nonetheless, given the obvious utility of this simple correlation analysis and the perturbation analysis of Sect. 3.2, it is surprising that they are not more widely used in hydrological modeling.

Despite the improved identifiability of the parameter space, however, it is still not possible to constrain the mean transit time by calibration to the hydrograph. As the bottom row of scatterplots in Fig. B2 shows, the MTT is almost entirely determined by the lower box's reference volume $S_{1, \text { ref }}$, as one would expect from Eq. (14). However, as predicted by the perturbation analysis in Sect. 3.2, and as shown by Fig. B2, the runoff response of the model system is essentially independent of $S_{1, \text { ref }}$ and therefore cannot be used to constrain it. The runoff response does depend on the ratio of $S_{1 \text {,ref }}$ to $b_{1}$, and thus can be used to constrain that ratio, but it cannot constrain $S_{1, \text { ref }}$ by itself, and thus it cannot constrain the MTT. For the young water fraction $F_{\mathrm{yw}}$ the outlook is not quite as bleak, because $F_{\mathrm{yw}}$ is correlated with the partition coefficient $\eta$, which can be constrained somewhat by calibration. As a result, it appears that $F_{\mathrm{yw}}$ could potentially be constrained within roughly $1 / 3$ of its full range by parameter calibration to the hydrograph.

Figure B3 provides a different visualization of the same equifinality problem. Figure B3 shows a 2-year excerpt from the simulated time series of streamflows, tracer concentrations, young water fractions, and mean transit times for the reference parameter set (the blue curves), along with the 50 parameter sets that gave the best fit to the reference hy- 
drograph (the gray curves). Because these 50 parameter sets were those that matched the reference hydrograph best, it is unsurprising that the 50 gray hydrographs generally follow the blue reference hydrograph in Fig. B3a. The 50 gray tracer concentration time series also follow the blue reference time series (Fig. B3b), but with somewhat greater variability than the hydrographs, indicating that the parameter values affect the chemographs and the hydrographs in somewhat different ways. But the most striking feature of Fig. B3 is the much greater variability among the young water fractions $F_{\mathrm{yw}}$ and (especially) the MTTs for these same parameter sets (Fig. B3c, d). Although all the parameter sets fit the reference hydrograph nearly perfectly, they vary over a range of 0.3 in $F_{\mathrm{yw}}$ (out of a total possible range of 1.0) and over a factor of 9.5 in MTT, on average, for the whole time period. Thus, these time series demonstrate, consistent with Fig. B2, that there are wide ranges of variability in $F_{\mathrm{yw}}$ and especially MTT that cannot be constrained by calibration to the hydrograph. 
Acknowledgements. I thank Scott Jasechko and Jeff McDonnell for the intensive discussions that motivated this analysis, and Markus Weiler and an anonymous reviewer for their comments. I thank the Centre for Ecology and Hydrology for making the Plynlimon data available.

Edited by: T. Bogaard

\section{References}

Benettin, P., van der Velde, Y., van der Zee, S., Rinaldo, A., and Botter, G.: Chloride circulation in a lowland catchment and the formulation of transport by travel time distributions, Water Resour. Res., 49, 4619-4632, doi:10.1002/wrcr.20309, 2013.

Benettin, P., Kirchner, J., Rinaldo, A., and Botter, G.: Modeling chloride transport using travel-time distributions at Plynlimon, Wales, Water Resour. Res., 51, 3259-3276, doi:10.1002/2014WR016600, 2015.

Bethke, C. M., and Johnson, T. M.: Groundwater age and groundwater age dating, Annu. Rev. Earth Planet. Sci., 36, 121-152, doi:10.1146/annurev.earth.36.031207.124210, 2008.

Beven, K.: On subsurface stormflow: predictions with simple kinematic theory for saturated and unsaturated flows, Water Resour. Res., 18, 1627-1633, 1982.

Beven, K.: A manifesto for the equifinality thesis, J. Hydrol., 320, 18-36, doi:10.1016/j.jhydrol.2005.07.007, 2006.

Birkel, C., Soulsby, C., and Tetzlaff, D.: Modelling catchment-scale water storage dynamics: reconciling dynamic storage with tracerinferred passive storage, Hydrol. Process., 25, 3924-3936, 2011.

Birkel, C., Soulsby, C., Tetzlaff, D., Dunn, S., and Spezia, L.: Highfrequency storm event isotope sampling reveals time-variant transit time distributions and influence of diurnal cycles, Hydrol. Process., 26, 308-316, doi:10.1002/hyp.8210, 2012.

Botter, G.: Catchment mixing processes and travel time distributions, Water Resour. Res., 48, 15, W05545, doi:10.1029/2011wr011160, 2012.

Botter, G., Bertuzzo, E., and Rinaldo, A.: Transport in the hydrological response: Travel time distributions, soil moisture dynamics, and the old water paradox, Water Resour. Res., 46, W03514, doi:10.1029/2009WR008371, 2010.

Botter, G., Bertuzzo, E., and Rinaldo, A.: Catchment residence and travel time distributions: The master equation, Geophys. Res. Lett., 38, L11403, doi:10.1029/2011GL047666, 2011.

Clark, M. P. and Kavetski, D.: Ancient numerical daemons of conceptual hydrological modeling: 1. Fidelity and efficiency of time stepping schemes, Water Resour. Res., 46, W10510, doi:10.1029/2009wr008894, 2010.

Duan, Q., Schaake, J., Andreassian, V., Franks, S., Goteti, G., Gupta, H. V., Gusev, Y. M., Habets, F., Hall, A., Hay, L., Hogue, T., Huang, M., Leavesley, G., Liang, X., Nasonova, O. N., Noilhan, J., Oudin, L., Sorooshian, S., Wagener, T., and Wood, E. F.: Model Parameter Estimation Experiment (MOPEX): An overview of science strategy and major results from the second and third workshops, J. Hydrol., 320, 3-17, doi:10.1016/j.jhydrol.2005.07.031, 2006.

Feng, X. H., Faiia, A. M., and Posmentier, E. S.: Seasonality of isotopes in precipitation: A global perspective, J. Geophys. Res.Atmos., 114, D08116, doi:10.1029/2008jd011279, 2009.
Harman, C. J.: Time-variable transit time distributions and transport: Theory and application to storage-dependent transport of chloride in a watershed, Water Resour. Res., 51, 1-30, doi:10.1002/2014WR015707, 2015.

Heidbüchel, I., Troch, P. A., Lyon, S. W., and Weiler, M.: The master transit time distribution of variable flow systems, Water Resour. Res., 48, W06520, doi:10.1029/2011WR011293, 2012.

Hrachowitz, M., Soulsby, C., Tetzlaff, D., Malcolm, I. A., and Schoups, G.: Gamma distribution models for transit time estimation in catchments: Physical interpretation of parameters and implications for time-variant transit time assessment, Water Resour. Res., 46, W10536, doi:10.1029/2010wr009148, 2010.

Hrachowitz, M., Savenije, H., Bogaard, T. A., Tetzlaff, D., and Soulsby, C.: What can flux tracking teach us about water age distribution patterns and their temporal dynamics?, Hydrol. Earth Syst. Sci., 17, 533-564, doi:10.5194/hess-17-533-2013, 2013.

Ibbitt, R. P. and O'Donnell, T.: Designing conceptual catchment models for automatic fitting methods, in: Mathematical Models in Hydrology, International Association of Hydrological Sciences Publication, Wallingford, UK, 461-475, 1974.

Kavetski, D. and Clark, M. P.: Ancient numerical daemons of conceptual hydrological modeling: 2. Impact of time stepping schemes on model analysis and prediction, Water Resour. Res., 46, W10511, doi:10.1029/2009wr008896, 2010.

Kavetski, D. and Clark, M. P.: Numerical troubles in conceptual hydrology: Approximations, absurdities and impact on hypothesis testing, Hydrol. Process., 25, 661-670, doi:10.1002/hyp.7899, 2011.

Kirchner, J. W.: A double paradox in catchment hydrology and geochemistry, Hydrol. Process., 17, 871-874, 2003.

Kirchner, J. W.: Catchments as simple dynamical systems: catchment characterization, rainfall-runoff modeling, and doing hydrology backward, Water Resour. Res., 45, W02429, doi:10.1029/2008WR006912, 2009.

Kirchner, J. W.: Aggregation in environmental systems - Part 1: Seasonal tracer cycles quantify young water fractions, but not mean transit times, in spatially heterogeneous catchments, Hydrol. Earth Syst. Sci., 20, 279-297, doi:10.5194/hess-20-2792016, 2016.

Kirchner, J. W., Feng, X., and Neal, C.: Fractal stream chemistry and its implications for contaminant transport in catchments, Nature, 403, 524-527, 2000.

Kirchner, J. W., Feng, X., and Neal, C.: Catchment-scale advection and dispersion as a mechanism for fractal scaling in stream tracer concentrations, J. Hydrol., 254, 81-100, 2001.

Kreft, A. and Zuber, A.: On the physical meaning of the dispersion equation and its solutions for different initial and boundary conditions, Chem. Eng. Sci., 33, 1471-1480, 1978.

McDonnell, J. J. and Beven, K.: Debates-The future of hydrological sciences: A (common) path forward? A call to action aimed at understanding velocities, celerities and residence time distributions of the headwater hydrograph, Water Resour. Res., 50, 5342-5350, doi:10.1002/2013wr015141, 2014.

McGuire, K. J. and McDonnell, J. J.: A review and evaluation of catchment transit time modeling, J. Hydrol., 330, 543-563, 2006.

Neal, C., Wilkinson, J., Neal, M., Harrow, M., Wickham, H., Hill, L., and Morfitt, C.: The hydrochemistry of the headwaters of the River Severn, Plynlimon, Hydrol. Earth Syst. Sci., 1, 583-617, doi:10.5194/hess-1-583-1997, 1997. 
Neal, C., Reynolds, B., Norris, D., Kirchner, J. W., Neal, M., Rowland, P., Wickham, H., Harman, S., Armstrong, L., Sleep, D., Lawlor, A., Woods, C., Williams, B., Fry, M., Newton, G., and Wright, D.: Three decades of water quality measurements from the Upper Severn experimental catchments at Plynlimon, Wales: an openly accessible data resource for research, modelling, environmental management and education, Hydrol. Process., 25, 3818-3830, doi:10.1002/hyp.8191, 2011.

Peters, N. E., Burns, D. A., and Aulenbach, B. T.: Evaluation of high-frequency mean streamwater transit-time estimates using groundwater age and dissolved silica concentrations in a small forested watershed, Aquat. Geochem., 20, 183-202, 2014.

Seeger, S. and Weiler, M.: Reevaluation of transit time distributions, mean transit times and their relation to catchment topography, Hydrol. Earth Syst. Sci., 18, 4751-4771, doi:10.5194/hess-184751-2014, 2014.
Tetzlaff, D., Malcolm, I. A., and Soulsby, C.: Influence of forestry, environmental change and climatic variability on the hydrology, hydrochemistry and residence times of upland catchments, J. Hydrol., 346, 93-111, 2007.

Van der Velde, Y., De Rooij, G. H., Rozemeijer, J. C., van Geer, F. C., and Broers, H. P.: The nitrate response of a lowland catchment: on the relation between stream concentration and travel time distribution dynamics, Water Resour. Res., 46, W11534, doi:10.1029/2010WR009105, 2010.

Van der Velde, Y., Torfs, P. J. J. F., van der Zee, S. E. A. T. M., and Uijlenhoet, R.: Quantifying catchment-scale mixing and its effect on time-varying travel time distributions, Water Resour. Res., 48, W06536, doi:10.1029/2011WR011310, 2012. 